Check for updates

Cite this: Phys. Chem. Chem. Phys., 2021, 23, 20419

\title{
An experimental and master-equation modeling study of the kinetics of the reaction between resonance-stabilized $\left(\mathrm{CH}_{3}\right)_{2} \mathrm{CCHCH}_{2}$ radical and molecular oxygen $\dagger$
}

\author{
Satya P. Joshi, Timo T. Pekkanen, Prasenjit Seal, (D) Raimo S. Timonen and \\ Arkke J. Eskola (D) *
}

\begin{abstract}
The kinetics of the reaction between resonance-stabilized $\left(\mathrm{CH}_{3}\right)_{2} \mathrm{CCHCH}_{2}$ radical $(\mathrm{R})$ and $\mathrm{O}_{2}$ has been investigated using photoionization mass spectrometry, and master equation (ME) simulations were performed to support the experimental results. The kinetic measurements of the $\left(\mathrm{CH}_{3}\right)_{2} \mathrm{CCHCH}_{2}+\mathrm{O}_{2}$ reaction (1) were carried out at low helium bath-gas pressures (0.2-5.7 Torr) and over a wide temperature range (238-660 K). Under low temperature (238-298 K) conditions, the pressure-dependent bimolecular association reaction $\mathrm{R}+\mathrm{O}_{2} \rightarrow \mathrm{ROO}$ determines kinetics, until at an intermediate temperature range (325$373 \mathrm{~K}$ ) the ROO adduct becomes thermally unstable and increasingly dissociates back to the reactants with increasing temperature. The initial association of $\mathrm{O}_{2}$ with $\left(\mathrm{CH}_{3}\right)_{2} \mathrm{CCHCH}_{2}$ radical occurs on two distinct sites: terminal $1(\mathrm{t})$ and non-terminal $1(\mathrm{nt})$ sites on $\mathrm{R}$, leading to the barrierless formation of $\mathrm{ROO}_{(\mathrm{t})}$ and $\mathrm{ROO}_{(\mathrm{nt})}$ adducts, respectively. Important for autoignition modelling of olefinic compounds, bimolecular reaction channels appear to open for the $\mathrm{R}+\mathrm{O}_{2}$ reaction at high temperatures $(T>500 \mathrm{~K})$ and pressureindependent bimolecular rate coefficients of reaction (1) with a weak positive temperature dependence, (2.8-4.6) $\times 10^{-15} \mathrm{~cm}^{3}$ molecule $\mathrm{s}^{-1} \mathrm{~s}^{-1}$, were measured in the temperature range of 500-660 $\mathrm{K}$. At a temperature of $501 \mathrm{~K}$, a product signal of reaction (1) was observed at $\mathrm{m} / \mathrm{z}=68$, probably originating from isoprene. To explore the reaction mechanism of reaction (1), quantum chemical calculations and ME simulations were performed. According to the ME simulations, without any adjustment to energies, the most important and second most important product channels at the high temperatures are isoprene + $\mathrm{HO}_{2}$ (yield > 91\%) and (2R/S)-3-methyl-1,2-epoxybut-3-ene $+\mathrm{OH}$ (yield $<8 \%$ ). After modest adjustments to $\mathrm{ROO}_{(\mathrm{t})}$ and $\mathrm{ROO}(\mathrm{nt})$ well-depths $\left(\sim 0.7 \mathrm{kcal} \mathrm{mol}^{-1}\right.$ each) and barrier height for the transition state associated with the kinetically most dominant channel, $\mathrm{R}+\mathrm{O}_{2} \rightarrow$ isoprene $+\mathrm{HO}_{2}\left(\sim 2.2 \mathrm{kcal} \mathrm{mol}^{-1}\right)$, the ME model was able to reproduce the experimental findings. Modified Arrhenius expressions for the kinetically important reaction channels are enclosed to facilitate the use of current results in combustion models.
\end{abstract}

Received 19th May 2021, Accepted 2nd August 2021

DOI: $10.1039 / \mathrm{d} 1 \mathrm{cp} 02210 \mathrm{e}$

rsc.li/pccp fuel consumption. ${ }^{1,2}$ Olefins contain one or more $\mathrm{C}=\mathrm{C}$ double bond in their molecular structure, which results in high thermal stability under combustion conditions. This, combined with high thermal stability of radicals formed from olefins, partly explains the soot-forming propensity of olefins under fuel-rich combustion conditions. ${ }^{3-5}$ In addition to soot formation affinity, autoignition chemistry and oxidation kinetics of olefins and olefinic radicals differ significantly from those of similar-size alkanes and alkyl radicals. ${ }^{6}$ Recently, olefin flame chemistry, ${ }^{7-9}$ pyrolysis, ${ }^{10,11}$ ignition delay times, ${ }^{12-15}$ and oxidation in jet-stirredreactor (JSR) ${ }^{16-18}$ experiments have received attention. However, little is still known experimentally about the oxidation kinetics of olefinic hydrocarbon radicals larger than allyl ${ }^{19,20}$ and methylvinyl $^{21}$ (i.e. $>\mathrm{C}_{3}$ ), which can be expected to play an important role in autoignition and oxidation of real fuels under 
low-temperature-combustion (LTC) conditions. Real scarcity exists on kinetic oxidation experiments of allyl-type, resonance-stabilized radicals larger than 1- and 2-methylallyl radicals (i.e. $>\mathrm{C}_{4}$ ). ${ }^{22,23}$

In this work, we focus on the oxidation kinetics of the allyltype, resonance-stabilized $\left(\mathrm{CH}_{3}\right)_{2} \mathrm{CCHCH}_{2}$ (2-methylbut-3-en-2-yl) radical. A potential source of this radical is a $\mathrm{H}$-atom abstraction from 2-methyl-2-butene (2M2B) as well as pyrolysis and decomposition reactions of larger olefinic fuel constituents. $2 \mathrm{M} 2 \mathrm{~B}$ is a potential surrogate fuel for the combustion modeling of real fuels. As discussed by Westbrook et al., ${ }^{16}$ under typical combustion conditions $\mathrm{H}$-atom abstraction reactions of small radical species (e.g. $\mathrm{H}, \mathrm{O}, \mathrm{OH}, \mathrm{CH}_{3}, \mathrm{CH}_{3} \mathrm{OO}$ etc.) from $2 \mathrm{M} 2 \mathrm{~B}$ is an important, if not crucial, route to initiate $2 \mathrm{M} 2 \mathrm{~B}$ oxidation. These reactions abstract $\mathrm{H}$-atoms by breaking weak allylic $\mathrm{C}-\mathrm{H}$ bonds (BDE $\sim 89 \mathrm{kcal} \mathrm{mol}^{-1}$ ) much more likely than the stronger vinylic $\mathrm{C}-\mathrm{H}$ bond ( $\mathrm{BDE} \sim 108 \mathrm{kcal} \mathrm{mol}^{-1}$ ), resulting in production of two distinct allyl-type pentenyl radicals, as shown in Scheme 1.

Both these allyl-type radicals, $\mathrm{CH}_{2}\left(\mathrm{CH}_{3}\right) \mathrm{CCHCH}_{3}$ and $\left(\mathrm{CH}_{3}\right)_{2} \mathrm{CCHCH}_{2}$, are resonantly stabilized. Their (and allyl-type radical $\mathrm{R}_{\mathrm{A}}$ in general) reaction with molecular oxygen $\left(\mathrm{O}_{2}\right)$ has a characteristically shallow $\mathrm{R}_{\mathrm{A}}+\mathrm{O}_{2} \rightarrow \mathrm{R}_{\mathrm{A}} \mathrm{OO}$ barrierless association reaction well-depth $\left(\sim 20 \mathrm{kcal} \mathrm{mol}^{-119,24}\right.$ compared to $\sim 40 \mathrm{kcal} \mathrm{mol}^{-1}$ for vinyl-type radicals $\left.{ }^{25,26}\right)$. This enables thermal decomposition of the $\mathrm{R}_{\mathrm{A}} \mathrm{OO}$ adduct back to the reactants to start to compete with the forward association reaction already at relatively low temperatures, establishing the chemical equilibrium $\mathrm{R}_{\mathrm{A}}+\mathrm{O}_{2} \rightleftharpoons \mathrm{R}_{\mathrm{A}} \mathrm{OO}$. Upon increasing temperature, this may eventually lead to conditions with almost no net reaction, until a new reaction channel for the $\mathrm{R}_{\mathrm{A}}+\mathrm{O}_{2}$ reaction, potentially, but not necessarily, becomes accessible at higher temperatures. For example, even at temperatures as high as $700 \mathrm{~K}$, only an upper limit of $2 \times 10^{-16} \mathrm{~cm}^{3}$ molecule ${ }^{-1} \mathrm{~s}^{-1}$ for the bimolecular rate coefficient of the $\mathrm{CH}_{3} \mathrm{CHCHCH}_{2}+\mathrm{O}_{2}$ reaction has been measured. ${ }^{22}$ In their JSR measurements of 2M2B oxidation in the temperature range $600-1100 \mathrm{~K}$ and at about $1 \mathrm{~atm}$ pressure with residence time $1.5 \mathrm{~s}$, Westbrook et $a l .{ }^{16}$ observed only a little reactivity below $800 \mathrm{~K}$, above which a rapid increase in the fuel consumption was observed. Under LTC conditions $(500<T<1000 \mathrm{~K})$, one may typically expect a fuel-radical $+\mathrm{O}_{2}$ reaction to constitute the major sink reaction of fuel-radical until unimolecular thermal decomposition reactions become accessible. However, in case of allyl-type radicals this is not necessarily the case (as discussed above for the $\mathrm{CH}_{3} \mathrm{CHCHCH}_{2}+\mathrm{O}_{2}$ reaction), and for this reason kinetic oxidation experiments with still larger $\mathrm{C}_{5}$ allyl-type radicals are of great importance.

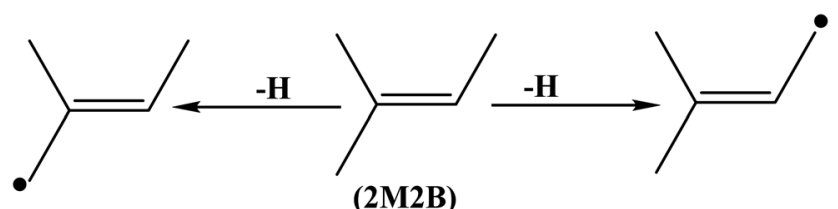

Scheme 1 Two allyl-type pentenyl radicals, $\mathrm{CH}_{2}\left(\mathrm{CH}_{3}\right) \mathrm{CCHCH}_{3}$ and $\left(\mathrm{CH}_{3}\right)_{2} \mathrm{CCHCH}_{2}$, produced via $\mathrm{H}$-atom abstraction reactions from 2methyl-2-butene (2M2B).

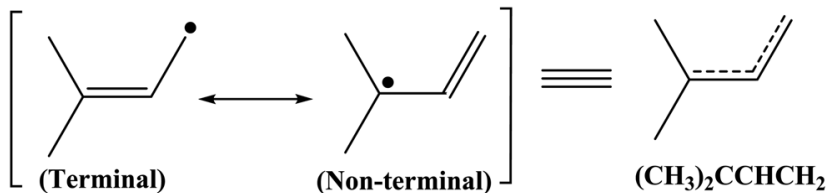

Scheme 2 Resonance structures contributing to the resonance hybrid structure of the $\left(\mathrm{CH}_{3}\right)_{2} \mathrm{CCHCH}_{2}$ radical.

In this work, we have studied the kinetics of the $\left(\mathrm{CH}_{3}\right)_{2} \mathrm{CCHCH}_{2}(\mathrm{R})+\mathrm{O}_{2}$ reaction (1) over a wide 238-660 K temperature range and at low pressures (0.2-5.7 Torr), as well as thermochemistry of the $\left(\mathrm{CH}_{3}\right)_{2} \mathrm{CCHCH}_{2}+\mathrm{O}_{2}$ $\left(\mathrm{CH}_{3}\right)_{2} \mathrm{CCHCH}_{2} \mathrm{OO}$ reaction (1a,-1a) in a narrower temperature range using photoionization mass spectrometry.

As shown in Scheme (2), the resonance hybrid structure of the $\left(\mathrm{CH}_{3}\right)_{2} \mathrm{CCHCH}_{2}$ radical is composed of two resonance structures. The association of $\mathrm{O}_{2}$ with either the terminal $(\mathrm{t})$ or non-terminal (nt) radical site of the $\left(\mathrm{CH}_{3}\right)_{2} \mathrm{CCHCH}_{2}$ radical generates $\mathrm{ROO}_{(\mathrm{t})}$ and $\mathrm{ROO}_{(\mathrm{nt})}$ adducts, respectively, conveniently denoted as $\left(\mathrm{CH}_{3}\right)_{2} \mathrm{CCHCH}_{2} \mathrm{OO}$ in reaction $(1 \mathrm{a},-1 \mathrm{a})$.

The kinetic measurements performed in this work were focused on providing accurate bimolecular rate coefficient and equilibrium constant data of reaction (1). Subsequently, high-level quantum chemistry calculations and master equation (ME) modeling of reaction (1) were performed to complement the measured bimolecular rate coefficient and thermochemistry data.

\section{Experimental}

Experiments were performed using a laminar flow-reactor coupled with a photoionization mass spectrometer (PIMS). A thorough description of the employed PIMS apparatus has been presented previously, ${ }^{27}$ so only the specific details concerning the current measurements are discussed here.

Photolysis of 1-bromo-3-methyl-2-butene or 1-chloro-3methyl-2-butene precursor at $248 \mathrm{~nm}$ radiation was performed using MPB ASX-750 or Coherent COMPex 201F excimer laser, respectively, to achieve a homogeneous $\left[\left(\mathrm{CH}_{3}\right)_{2} \mathrm{CCHCH}_{2}\right]$ along the flow-reactor axis.

$$
\begin{aligned}
\left(\mathrm{CH}_{3}\right)_{2} \mathrm{CCHCH}_{2} \mathrm{Br}+h \nu_{248 \mathrm{~nm}} & \rightarrow\left(\mathrm{CH}_{3}\right)_{2} \mathrm{CCHCH}_{2}+\mathrm{Br} \\
& \rightarrow \text { Other products } \\
\left(\mathrm{CH}_{3}\right)_{2} \mathrm{CCHCH}_{2} \mathrm{Cl}+h \nu_{248 \mathrm{~nm}} & \rightarrow\left(\mathrm{CH}_{3}\right)_{2} \mathrm{CCHCH}_{2}+\mathrm{Cl} \\
& \rightarrow \text { Other products }
\end{aligned}
$$

The measurements presented in this study were primarily conducted using the bromide precursor, while the chloride precursor, which has a higher $\mathrm{BDE}(\mathrm{C}-\mathrm{Cl})$ compared to $\mathrm{BDE}(\mathrm{C}-\mathrm{Br})$, was principally used to show that the kinetic results do not depend on the selected photolytic precursor. Due to the smaller absorption cross-section of $\left(\mathrm{CH}_{3}\right)_{2} \mathrm{CCHCH}_{2} \mathrm{Cl}$ at $248 \mathrm{~nm}$ in comparison to $\left(\mathrm{CH}_{3}\right)_{2} \mathrm{CCHCH}_{2} \mathrm{Br}$, experiments using the chloride precursor required higher $\left[\left(\mathrm{CH}_{3}\right)_{2} \mathrm{CCHCH}_{2} \mathrm{Cl}\right]$ and 


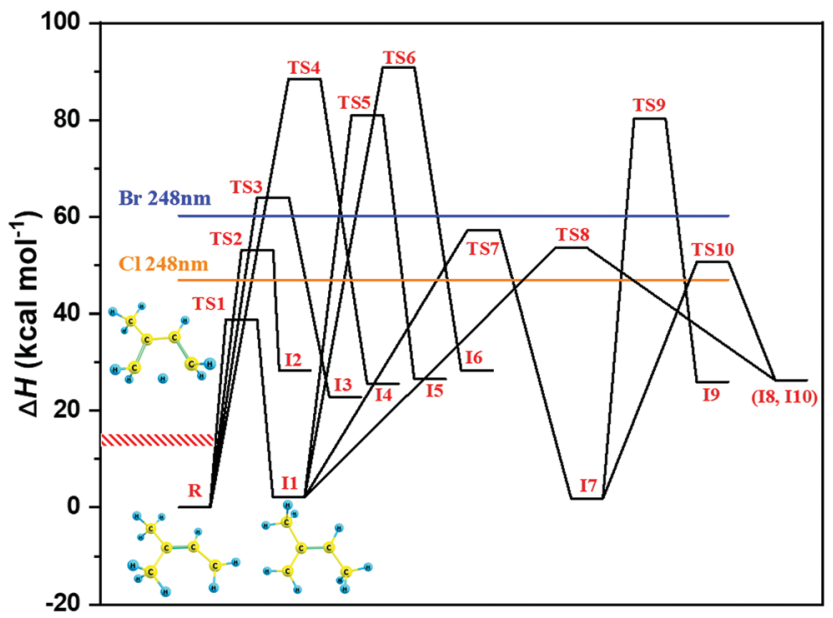

Fig. 1 Relative enthalpies $\left(\Delta H_{(298 k)}\right)$ of the various $\left(\mathrm{CH}_{3}\right)_{2} \mathrm{CCHCH}_{2}$ radical isomers and the connecting transition states (TS) calculated at the MN15/ccpVTZ level. The colored horizontal lines represent the difference between the $248 \mathrm{~nm}$ photon energy and the calculated $\mathrm{BDE}$ of $\mathrm{Br}-\mathrm{C}$ and $\mathrm{Cl}-\mathrm{C}$ bonds for $\left(\mathrm{CH}_{3}\right)_{2} \mathrm{CCHCH}_{2} \mathrm{Br}\left(\mathrm{BDE}_{(\mathrm{MN} 15 / \mathrm{cc}-\mathrm{pVTZ})}=55.1 \mathrm{kcal} \mathrm{mol}^{-1}\right)$ and $\left(\mathrm{CH}_{3}\right)_{2} \mathrm{CCHCH}_{2} \mathrm{Cl}$ $\left(\mathrm{BDE}_{(\mathrm{MN15} / \mathrm{cc}-\mathrm{pVTZ})}=68.4 \mathrm{kcal} \mathrm{mol}^{-1}\right)$ precursors, respectively. The red, shaded area shows our best estimate on excitation energy of the $\left(\mathrm{CH}_{3}\right)_{2} \mathrm{CCHCH}_{2}$ radicals after photolysis of $\left(\mathrm{CH}_{3}\right)_{2} \mathrm{CCHCH}_{2} \mathrm{Br}$ and $\left(\mathrm{CH}_{3}\right)_{2} \mathrm{CCHCH}_{2} \mathrm{Cl}$ precursors at $248 \mathrm{~nm}$ wavelength, respectively. The optimized geometries and $\Delta H_{(298 k)}$ values of the stationary points are given in the ESI $\dagger$ (see Fig. S1).

higher laser fluences $\left[\sim 170 \mathrm{~mJ} \mathrm{~cm}^{-2}\right]$ than measurements using the bromide precursor, where lower precursor concentrations and laser fluences $\left[\sim 17-50 \mathrm{~mJ} \mathrm{~cm}^{-2}\right]$ were used. We estimate that $\left[\left(\mathrm{CH}_{3}\right)_{2} \mathrm{CCHCH}_{2}\right]_{t=0} \leq 3 \times 10^{11} \mathrm{~cm}^{-3}$ in the kinetic measurements using either precursor.

Producing the same $\left(\mathrm{CH}_{3}\right)_{2} \mathrm{CCHCH}_{2}$ radical by photolysing two different precursors, $\left(\mathrm{CH}_{3}\right)_{2} \mathrm{CCHCH}_{2} \mathrm{Br}$ and $\left(\mathrm{CH}_{3}\right)_{2} \mathrm{CCHCH}_{2} \mathrm{Cl}$, with the same $248 \mathrm{~nm}$ energy photons enables to some extent testing a potential isomerization of nascent $\left(\mathrm{CH}_{3}\right)_{2} \mathrm{CCHCH}_{2}$ radicals immediately after photolysis before their thermalization. Fig. 1 presents relative enthalpies $\left(\Delta H_{(298 \mathrm{~K})}\right)$ of the various $\left(\mathrm{CH}_{3}\right)_{2} \mathrm{CCHCH}_{2}$ radical isomers and the transition states (TS) connecting them as well as maximum internal energies of the radicals after $248 \mathrm{~nm}$ photolysis of $\left(\mathrm{CH}_{3}\right)_{2} \mathrm{CCHCH}_{2} \mathrm{Br}$ and $\left(\mathrm{CH}_{3}\right)_{2} \mathrm{CCHCH}_{2} \mathrm{Cl}$ precursors (full horizontal lines), all calculated at the MN15/cc-pVTZ level in this work. In a recent study by this group, Döntgen et al. ${ }^{24}$ investigated the kinetics of the $\mathrm{CH}_{2} \mathrm{CHCHCH}_{2} \mathrm{CH}_{3}+\mathrm{O}_{2}$ reaction and utilized $248 \mathrm{~nm}$ photolysis of $\mathrm{BrCH}_{2} \mathrm{CHCHCH}_{2} \mathrm{CH}_{3}$ and $\mathrm{ClCH}_{2} \mathrm{CHCHCH}_{2} \mathrm{CH}_{3}$ precursors for radical production. They performed time-dependent density functional theory calculations for electronic excitation energies of the bromide and chloride precursors and concluded that the total vibrational excitation of the $\mathrm{CH}_{2} \mathrm{CHCHCH}_{2} \mathrm{CH}_{3}$ radical after photolysis is about 15.0 and $13.4 \mathrm{kcal} \mathrm{mol}^{-1}$ for the bromide and chloride precursors, respectively. Both these energies were significantly below the $\sim 37 \mathrm{kcal} \mathrm{mol}^{-1}$ energy required for the lowest-energy $\mathrm{CH}_{2} \mathrm{CHCHCH}_{2} \mathrm{CH}_{3} \rightarrow \mathrm{CH}_{3} \mathrm{CHCHCHCH}_{3}$ isomerization in the system, showing that in those experiments only one isomer was produced during photolysis. Considering the very close similarity between those and the current experiments, i.e. the same photolysis energy and especially very similar photolytic precursors (e.g. $\mathrm{BrCH}_{2} \mathrm{CHCHCH}_{2} \mathrm{CH}_{3}$ vs. $\left(\mathrm{CH}_{3}\right)_{2} \mathrm{CCHCH}_{2} \mathrm{Br}$ and $\mathrm{ClCH}_{2} \mathrm{CHCHCH}_{2} \mathrm{CH}_{3}$ vs. $\left.\left(\mathrm{CH}_{3}\right)_{2} \mathrm{CCHCH}_{2} \mathrm{Cl}\right)$, we estimate that the post-photolysis vibrational excitation of the $\left(\mathrm{CH}_{3}\right)_{2} \mathrm{CCHCH}_{2}$ radical is also about 15.0 and $13.4 \mathrm{kcal} \mathrm{mol}^{-1}$ for the bromide and chloride precursors, respectively. Both these values, which contain some uncertainty due to the above estimation, are significantly below the calculated energy of the lowest isomerization transition state, TS1 = $38.9 \mathrm{kcal} \mathrm{mol}^{-1}$, see Fig. 1. The experimental conditions and the results of the kinetic measurements using chlorine and bromine precursors are presented in Tables 2-4.

The reaction mixture flowing through the temperaturecontrolled flow-reactor consisted of a mainly inert bath-gas (Helium $>97 \%)$ along with radical precursor $\left(\left(\mathrm{CH}_{3}\right)_{2} \mathrm{CCHCH}_{2} \mathrm{Br}<0.02 \%\right.$, $\left.\left(\mathrm{CH}_{3}\right)_{2} \mathrm{CCHCH}_{2} \mathrm{Cl}<0.05 \%\right)$ and molecular oxygen $\left(\left[\mathrm{O}_{2}\right]<3 \%\right)$. In the high-temperature measurements a significantly higher amount of $\mathrm{O}_{2}(<51 \%)$ was used. Depending upon the temperature and pressure conditions employed during the measurements, different combinations of reactor tube sizes and coatings were used (see also Tables 2-4 caption): Pyrex-glass reactor (i.d. = $1.65 \mathrm{~cm}$ ) with polydimethylsiloxane (PDMS) or halocarbon wax (HW) coating, stainless steel reactor (i.d. $=1.7 \mathrm{~cm}$ or $0.8 \mathrm{~cm}$ ) with HW coating, and quartz reactor (i.d. $=0.85 \mathrm{~cm}$ ) with boric oxide coating. A set temperature of the reaction zone was maintained within a uniformity of $\pm 2 \mathrm{~K}$ using a PID controller.

The observed kinetics of the $\left(\mathrm{CH}_{3}\right)_{2} \mathrm{CCHCH}_{2}+\mathrm{O}_{2}$ reaction (1) at different temperatures can be characterized as follows.

$$
\begin{array}{r}
\left(\mathrm{CH}_{3}\right)_{2} \mathrm{CCHCH}_{2}+\mathrm{O}_{2} \stackrel{k_{1 \mathrm{a}}}{\longrightarrow}\left(\mathrm{CH}_{3}\right)_{2} \mathrm{CCHCH}_{2} \mathrm{OO} \\
\left(\mathrm{CH}_{3}\right)_{2} \mathrm{CCHCH}_{2}+\mathrm{O}_{2} \underset{k_{-1 \mathrm{a}}}{\stackrel{k_{1 \mathrm{a}}}{\longrightarrow}}\left(\mathrm{CH}_{3}\right)_{2} \mathrm{CCHCH}_{2} \mathrm{OO} \quad(1 \mathrm{a},-1 \mathrm{a}) \\
\left(\mathrm{CH}_{3}\right)_{2} \mathrm{CCHCH}_{2}+\mathrm{O}_{2} \underset{\mathrm{High} T}{\stackrel{k_{1 \mathrm{~b}}}{\longrightarrow}} \text { Products }
\end{array}
$$

Here, reaction (1a) represents the association reaction between the $\left(\mathrm{CH}_{3}\right)_{2} \mathrm{CCHCH}_{2}$ radical and $\mathrm{O}_{2}$ leading to the formation of $\left(\mathrm{CH}_{3}\right)_{2} \mathrm{CCHCH}_{2} \mathrm{OO}$ adducts. This reaction is important at low temperatures, 238-298 K. Reactions (1a,-1a) are important in the intermediate temperature range (325-373 K), where adducts become thermally unstable and a kinetic equilibrium is established between the forward bimolecular $\left(\mathrm{CH}_{3}\right)_{2} \mathrm{CCHCH}_{2}+\mathrm{O}_{2}$ reaction and the unimolecular dissociation of $\left(\mathrm{CH}_{3}\right)_{2} \mathrm{CCHCH}_{2} \mathrm{OO}$ adducts back to the reactants. Phenomenological reaction (1b) corresponds to new reaction channels that open for $\left(\mathrm{CH}_{3}\right)_{2} \mathrm{CCHCH}_{2}$ $+\mathrm{O}_{2}$ reaction at high temperatures $(>500 \mathrm{~K})$.

Apart from the reaction with $\mathrm{O}_{2}$, two other reactions that contribute to the $\left(\mathrm{CH}_{3}\right)_{2} \mathrm{CCHCH}_{2}$ radical decay under experimental conditions are heterogeneous wall losses and second order radical-radical decay processes.

$$
\begin{gathered}
\mathrm{R} \stackrel{\stackrel{k_{\text {wall }}^{(\mathrm{R})}}{\longrightarrow} \text { Heterogeneous loss }}{\mathrm{R}+\mathrm{R} \rightarrow \text { Products }} \\
\end{gathered}
$$

Contribution due to reaction (B) was minimized by reducing the laser intensity and/or photolytic precursor concentration until the measured decay rate was strictly single-exponential. 
Depending upon the temperature range of interest, different reactor coatings (i.e. PDMS, HW or boric oxide) were employed for minimizing the heterogeneous wall-decay rate coefficients $\left(k_{\text {wall }}^{(\mathrm{R})}\right)$ of the $\left(\mathrm{CH}_{3}\right)_{2} \mathrm{CCHCH}_{2}$ radical.

The detection of the $\left(\mathrm{CH}_{3}\right)_{2} \mathrm{CCHCH}_{2}$ radical decay profiles for reaction (1) was performed using the PIMS. The radiation of energy $8.44 \mathrm{eV}$ from a microwave-discharge of $6 \%$ xenon in a helium-mixture with a sapphire window to cut-off higher energy photons was used to ionize $\left(\mathrm{CH}_{3}\right)_{2} \mathrm{CCHCH}_{2}$ radicals present in the reaction mixture. Potential products of reaction (1b) were searched utilizing ionization radiation from a $\mathrm{H}_{2}$-lamp (discharge of $\mathrm{H}_{2}$ gas with an $\mathrm{MgF}_{2}$ window to produce radiation at around $10.2 \mathrm{eV}$ ). Ions formed were mass selected by a quadrupole mass spectrometer followed by the detection using an electron multiplier. Radical ion $\left(\mathrm{CH}_{3}\right)_{2} \mathrm{CCHCH}_{2}{ }^{+}$was detected at its parent mass at $m / z=69$. A temporal ion decay signal was recorded from $10 \mathrm{~ms}$ before to $50 \mathrm{~ms}$ after each laser pulse, and accumulated for 300015000 repetitions before transferring to a PC for further analysis.

A nonlinear least-squares-fitting method was used for fitting the observed $\left(\mathrm{CH}_{3}\right)_{2} \mathrm{CCHCH}_{2}$ radical decay profiles. For reactions (1a) and (1b) the measured radical decay profiles were fitted using the single-exponential expression: $\left[\mathrm{R}_{t}\right]=B+\left[\mathrm{R}_{0}\right] \times$ $\exp \left(-k_{1 \mathrm{a}, 1 \mathrm{~b}}^{\prime} t\right)$. Here, $k_{1 \mathrm{a}, 1 \mathrm{~b}}^{\prime}=k_{1 \mathrm{a}}^{\prime}$ or $k_{1 \mathrm{~b}}^{\prime}$, is directly related to the bimolecular rate coefficients of the reaction $\left(1 \mathrm{a} ; k_{1 \mathrm{a}}\right)$ and $\left(1 \mathrm{~b} ; k_{1 \mathrm{~b}}\right)$ via relation: $k_{1 \mathrm{a}, 1 \mathrm{~b}}^{\prime}=\left(k_{1 \mathrm{a}, 1 \mathrm{~b}} \times\left[\mathrm{O}_{2}\right]\right)+k_{\text {wall }}^{(\mathrm{R})} ; B$ is the background signal, and $\left[\mathrm{R}_{0}\right]$ and $\left[\mathrm{R}_{t}\right]$ are proportional to the initial $(t=0)$ and temporal radical concentration, respectively. Under conditions where kinetic equilibrium is established, a decay profile of a resonantly stabilized radical with two non-similar resonance structures follows, in principle, a tri-exponential behavior. However, following the scheme proposed by Knyazev et $a .^{22}$ for the kinetics of the $\mathrm{CH}_{3} \mathrm{CHCHCH}_{2}+\mathrm{O}_{2}$ reaction, such tri-exponential behavior can be fitted with a bi-exponential expression, $\left[R_{t}\right]=B+C \mathrm{e}^{-\lambda_{1} t}+D \mathrm{e}^{-\lambda_{2} t}$, which effectively leads to averaging the kinetic behavior of the two radical sites. Subsequently, the obtained fitted parameters (i.e. $C, D, \lambda_{1}, \lambda_{2}$ ) are used to calculate the forward $\left(k_{1 \mathrm{a}}\right)$ and backward $\left(k_{-1 \mathrm{a}}\right)$ rate coefficients of reaction $(1 \mathrm{a},-1 \mathrm{a})$ using the following equations.

$$
\begin{gathered}
k_{1 \mathrm{a}}\left[\mathrm{O}_{2}\right]=\frac{\left(\frac{C}{D}\right) \lambda_{1}+\lambda_{2}}{1+\left(\frac{C}{D}\right)}-k_{\text {wall }}^{(\mathrm{R})} \\
k_{-1 \mathrm{a}}=\lambda_{1}+\lambda_{2}-\left(k_{1 \mathrm{a}}\left[\mathrm{O}_{2}\right]\right)-k_{\text {wall }}^{(\mathrm{R})}-k_{\text {irr. }}^{(\mathrm{ROO})}
\end{gathered}
$$

Here, $k_{\mathrm{irr} .}^{(\mathrm{ROO})}$ represents the rate coefficients for irreversible first-order decay processes (including heterogeneous wall losses) related to ROO adducts, and is calculated using expression (E3).

$$
k_{\text {irr. }}^{(\mathrm{ROO})}=\frac{1}{k_{\mathrm{la}}\left[\mathrm{O}_{2}\right]}\left(\lambda_{1} \lambda_{2}-k_{\text {wall }}^{(\mathrm{R})} \frac{\left(\frac{C}{D}\right) \lambda_{2}+\lambda_{1}}{1+\left(\frac{C}{D}\right)}\right)
$$

The values for equilibrium-constants $\left(K_{\mathrm{eq}}\right)$ of reaction $(1 \mathrm{a},-1 \mathrm{a})$ were calculated using expression (E4).

$$
K_{\text {eq }}=\frac{k_{1 \mathrm{a}}}{k_{-1 \mathrm{a}}} \frac{P^{\circ} N_{\mathrm{A}}}{R T}
$$

Here, the standard pressure term $\left(P^{\circ}\right)$ is introduced to the (E4) for satisfying the definition of equilibrium-constant being a dimensionless quantity. The species involved are assumed to have an ideal gas behavior and their standard states are chosen at 1 bar pressure (i.e. $P^{\circ}=1$ bar), at a specified temperature. $R$ is the gas constant and $N_{\mathrm{A}}$ is the Avogadro's constant.

Before use, 1-bromo-3-methyl-2-butene (Sigma-Aldrich, purity $>95 \%$ ) and 1-chloro-3-methyl-2-butene (Sigma-Aldrich, purity $>95 \%$ ) were degassed by several freeze-pump-thaw cycles. Helium (Messer-Griesheim purity of 99.9996\%) and $\mathrm{O}_{2}$ (Aga, purity of $99.998 \%$ ) were used as supplied.

\section{Computational methods and master equation simulations}

We used the MN15 functional ${ }^{28}$ with the Def2TZVP basis set ${ }^{29}$ to locate the stationary points on the potential energy surface (PES) of reaction (1). The same level of theory was used to determine harmonic frequencies and to perform onedimensional hindered rotor scans ( 5 degree increments). The harmonic frequencies were scaled ${ }^{30}$ by a factor of 0.979 to partially account for anharmonic effects. Single-point energies were calculated for many of the stationary points at the ROHF$\operatorname{CCSD}(\mathrm{T})$ level of theory using the cc-pVDZ, cc-pVTZ, and ccpVQZ basis sets. ${ }^{31}$ The Hartree-Fock and correlation energies of the species were extrapolated to the complete basis set limit using relations (E5) and (E6), respectively. ${ }^{32,33}$

$$
\begin{gathered}
E_{\mathrm{HF}}(X)=E_{\mathrm{HF}}^{\mathrm{CBS}}+B_{\mathrm{HF}} \mathrm{e}^{-a_{\mathrm{HF}} \mathrm{X}} \\
E_{\text {corr }}(X)=E_{\text {corr }}^{\mathrm{CBS}}+B_{\text {corr }} X_{\text {corr }}{ }^{-a}
\end{gathered}
$$

Here $X$ is 2, 3, and 4 for the basis sets cc-pVDZ, cc-pVTZ, and cc-pVQZ, respectively and the $E^{\mathrm{CBS}}, B$, and $a$ parameters are obtained by solving a system of three equations. The MN15/ Def2TZVP and ROHF-CCSD(T)/CBS calculations were performed with Gaussian $16 .^{34}$

Multireference methods were used to evaluate the energies of some stationary points. We used the CASPT2 method with the cc-pVTZ and cc-pVQZ basis sets. For multireference calculations, we extrapolated the complete basis set $\left(\Delta E_{\text {total }}^{\mathrm{CBS}}\right)$ limit energy difference from the following relation. ${ }^{35}$

$$
\Delta E_{\text {total }}^{\mathrm{CBS}}=\Delta E_{\text {cc-pVQZ }}-\left(\left(\Delta E_{\text {cc-pVTZ }}-\Delta E_{\text {cc-pVQZ }}\right) \times 0.69\right)
$$

The ORCA software package (program version 4.2.0) ${ }^{36}$ was employed in these calculations using the default CASSCF/ CASPT2 settings. Notably, we did not use IPEA or level shifts. In a recent publication, Zobel et al. questioned the validity of the IPEA shift. ${ }^{37}$ In their investigation of excitation energies of organic molecules, they found that the ideal value of the IPEA shift correlated both with the size of the molecule and the basis 
set that was being used. Thus, the idea of there being an average IPEA shift value that improves the results for most systems seems unreasonable. Furthermore, for the benchmark set they were testing, they found that using the standard IPEA shift of 0.25 resulted in poorer agreement with experiment than not using an IPEA shift. Level shifts are typically used to avoid problems with intruder states. In our calculations, reference weights were between $0.7-0.8$, so intruder states should not be a problem and, therefore, level shifts are not needed. Details on active space selections are given in the results and discussion section.

In order to complement the measured bimolecular rate coefficients $\left(k_{1 \mathrm{a}}, k_{1 \mathrm{~b}}\right)$, ME simulations were performed on the associated PES. ME simulations were done using MESMER code (version 6.1) ${ }^{38}$ incorporating 1-D energy-grained ME treatment. Coupling between external and internal rotations can be treated classically, although potential coupling between internal rotors is not explicitly treated.

Since there are no well-defined transition states for the barrierless $\mathrm{R}+\mathrm{O}_{2} \rightarrow \mathrm{ROO}$ association reactions, ${ }^{24}$ we used the inverse-Laplace transform (ILT) method implemented in MESMER to compute the number of states of the variational transition states. The expression MESMER transforms is the modified Arrhenius expression of the canonical (high-pressure) association reaction rate coefficient. The Arrhenius parameters in the expression can be optimized using experimental data.

$$
k_{\infty}(T)=A\left(\frac{T}{T_{\text {ref }}}\right)^{m} \mathrm{e}^{-\frac{E_{\mathrm{a}}}{R T}}
$$

Here, $k_{\infty}(T)$ is the rate coefficient at the high pressure limit, $T$ is temperature, and $T_{\text {ref }}(=300 \mathrm{~K})$ is the reference temperature. $A, m$ and $E_{\mathrm{a}}$ are the pre-exponential factor, modified Arrhenius parameter and activation energy, respectively. Note that since reaction (1a) is considered to be a barrierless reaction, the activation energy in (E8) is approximated to be zero (i.e. $E_{\mathrm{a}}=0$ ). Microcanonical rate coefficients are calculated using RRKM theory.

MESMER utilizes a single-exponential-down model (E9) to account for the energy transfer via collisions between bath gas (i.e. helium in our case) and modelled species.

$$
\left\langle\Delta E_{\text {down }}\right\rangle=\left\langle\Delta E_{\text {down,ref }}\right\rangle\left(\frac{T}{T_{\text {ref }}}\right)^{n}
$$

Here, $\left\langle\Delta E_{\text {down }}\right\rangle$ corresponds to an average energy transferred from a higher energy grain to a lower energy grain in a single collision, and is used to calculate the associated collisional energy transfer probabilities. The $\left\langle\Delta E_{\text {down,ref }}\right\rangle$ and $n$ are the independent parameters representing the value of $\left\langle\Delta E_{\text {down }}\right\rangle$ at some reference temperature $\left(T_{\text {ref }}=300 \mathrm{~K}\right)$ and the temperature dependence of the $\left\langle\Delta E_{\text {down }}\right\rangle$, respectively. The Lennard-Jones (L-J) potential model was used for obtaining the collision frequencies governing the energetics of collisions between bath-gas and modelled species. The L-J parameters used for helium bathgas and the modeled species are shown in Table 1.
Table 1 L-J parameters for Helium bath-gas ${ }^{39}$ and $\mathrm{C}_{5} \mathrm{H}_{9} \mathrm{O}_{2}$ intermediates

\begin{tabular}{lll}
\hline Species & $\varepsilon(\mathrm{K})$ & $\sigma(\AA)$ \\
\hline Helium & 10.2 & 2.55 \\
$\mathrm{C}_{5} \mathrm{H}_{9} \mathrm{O}_{2}$ intermediates & 463 & 6.53
\end{tabular}

We used the online resources of Cantherm ${ }^{40}$ to estimate the L-J parameters of $\left(\mathrm{CH}_{3}\right)_{2} \mathrm{CCHCH}_{2} \mathrm{OOH}$ (2-methylbut-3-ene-2peroxol) and $\mathrm{HOO}\left(\mathrm{CH}_{3}\right)_{2} \mathrm{CCHCH}_{2}$ (3-methylbut-2-ene-1peroxol) with the Joback method. We averaged these values and assigned them to the $\mathrm{C}_{5} \mathrm{H}_{9} \mathrm{O}_{2}$ intermediates.

An energy grain size of $75 \mathrm{~cm}^{-1}$ was used in all MESMER simulations. The quantum-mechanical tunneling corrections for elementary steps involving intra-molecular $\mathrm{H}$-atom transfer were modelled using Eckart potential energy barriers.

Subsequently, using the experimental data as input, MESMER optimizes the fitting parameters for the modified Arrhenius eqn (E8) (i.e. parameters $A$ and $m$ ) and the collisional energy transfer model (i.e. parameters $\left\langle\Delta E_{\text {down,ref }}\right\rangle$ and $n$ ), by minimizing the value of $\chi^{2}\left(k_{1 \mathrm{a}} \text { (exp.) }-k_{1 \mathrm{a}}(\text { calc. })\right)^{2}$ using a built-in LevenbergMarquardt fitting algorithm (non-linear least-squares fitting method). The optimized ME model may then be used to extrapolate the kinetics of reaction (1) to experimentally inaccessible temperature and pressure conditions.

\section{Results and discussion}

The results of the kinetics measurements of the $\left(\mathrm{CH}_{3}\right)_{2} \mathrm{CCHCH}_{2}+$ $\mathrm{O}_{2}$ reaction (1) are categorized into low, intermediate, and high temperature region based on their kinetic behavior in the employed overall temperature range $238-660 \mathrm{~K}$ of the current work.

\section{Low and intermediate temperature range}

As can be seen in Fig. 2, the $\left(\mathrm{CH}_{3}\right)_{2} \mathrm{CCHCH}_{2}$ radical decay kinetics at $298 \mathrm{~K}$ and below in the low temperature range (238$298 \mathrm{~K}$ ) is single-exponential and is governed by the forward reaction (1a), $\left(\mathrm{CH}_{3}\right)_{2} \mathrm{CCHCH}_{2}+\mathrm{O}_{2} \rightarrow\left(\mathrm{CH}_{3}\right)_{2} \mathrm{CCHCH}_{2} \mathrm{OO}$. In the intermediate temperature range (325-373 $\mathrm{K})$, the dissociation of $\left(\mathrm{CH}_{3}\right)_{2} \mathrm{CCHCH}_{2} \mathrm{OO}$ adducts back to reactants (reaction $(-1 \mathrm{a})$ ) becomes increasingly important and results in the biexponential behavior of the observed $\left(\mathrm{CH}_{3}\right)_{2} \mathrm{CCHCH}_{2}$ radical decay signals.

A typical bimolecular plot for reaction (1a) in the low temperature range is shown in Fig. 3 and the plot represents the measured pseudo-first-order rate coefficients $\left(k_{1 \mathrm{a}}^{\prime}\right)$ as a function of the employed molecular oxygen concentration, $\left[\mathrm{O}_{2}\right]$.

We were not able to observe a $\left(\mathrm{CH}_{3}\right)_{2} \mathrm{CCHCH}_{2} \mathrm{OO}$ adduct $(\mathrm{m} / \mathrm{z}=101)$ formation signal, because ions of peroxy radicals (apart from $\mathrm{CH}_{3} \mathrm{OO}$ radical) are generally not stable and may instead dissociatively ionize to produce the parent radical ion (i.e. $\left(\mathrm{CH}_{3}\right)_{2} \mathrm{CCHCH}_{2}{ }^{+}$radical ion in the current case) among other products. ${ }^{41}$ For this reason, in our kinetic experiments we have utilized a low photon energy, $8.44 \mathrm{eV}$, radiation for ionization of $\left(\mathrm{CH}_{3}\right)_{2} \mathrm{CCHCH}_{2}$ radical $(\mathrm{m} / \mathrm{z}=69)$ and avoided any dissociative ionization of $\left(\mathrm{CH}_{3}\right)_{2} \mathrm{CCHCH}_{2} \mathrm{OO}$ adducts to the 


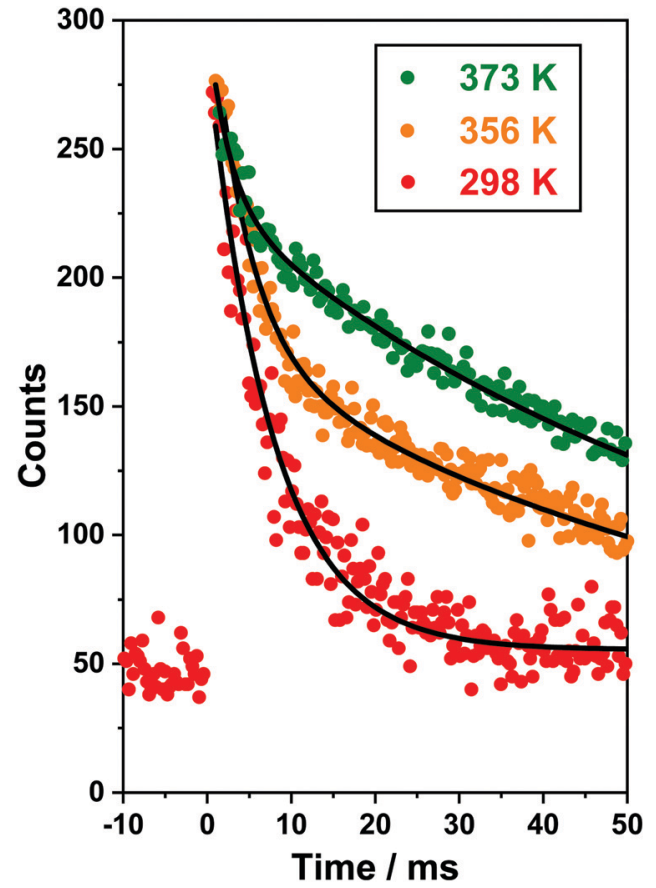

Fig. 2 A comparative plot for the measured $\left(\mathrm{CH}_{3}\right)_{2} \mathrm{CCHCH}_{2}$ radical decay signals obtained at three different temperatures at low (238-298 K) and intermediate $(325-373 \mathrm{~K})$ temperature ranges, reflecting the increasing importance of $\left(\mathrm{CH}_{3}\right)_{2} \mathrm{CCHCH}_{2} \mathrm{OO}$ adduct dissociation back to the reactants (via reaction $(-1 \mathrm{a})$ ) above $298 \mathrm{~K}$ temperature.

$m / z=69$ of the parent radical. This can be clearly observed from Fig. 2, where the signal at $\mathrm{m} / \mathrm{z}=69$ from the $\left(\mathrm{CH}_{3}\right)_{2} \mathrm{CCHCH}_{2}$ radical measured at $298 \mathrm{~K}$ decays back to the baseline.

For the low temperature range experiments, the measured pressure-dependent bimolecular rate coefficients $\left(k_{1 \mathrm{a}}\right)$ of reaction (1a) are shown in Table 2. Experiments were mainly performed using the $\left(\mathrm{CH}_{3}\right)_{2} \mathrm{CCHCH}_{2} \mathrm{Br}$ photolytic precursor. A few measurements using chloride precursor show that the measured $k_{1 \mathrm{a}}$ values are independent of the precursor used (i.e. $\left(\mathrm{CH}_{3}\right)_{2} \mathrm{CCHCH}_{2} \mathrm{Br}$ or $\left.\left(\mathrm{CH}_{3}\right)_{2} \mathrm{CCHCH}_{2} \mathrm{Cl}\right)$.

For the intermediate temperature range, the observed forward and backward rate coefficients of reactions (1a) and $(-1 \mathrm{a})$, along with respective natural logarithm of the equilibrium constants $\left(\ln \left(K_{\mathrm{eq}}\right)\right)$ are given in Table 3. The results of the intermediate temperature range measurements are also independent of the precursor $\left(\left(\mathrm{CH}_{3}\right)_{2} \mathrm{CCHCH}_{2} \mathrm{Br}\right.$ or $\left.\left(\mathrm{CH}_{3}\right)_{2} \mathrm{CCHCH}_{2} \mathrm{Cl}\right)$ used. The returned values of the fitting parameters associated with fitting the bi-exponential expression $\left[\mathrm{R}_{t}\right]=B+C \mathrm{e}^{-\lambda_{1} t}+D \mathrm{e}^{-\lambda_{2} t}$ to the decay traces are given in the ESI $\dagger$ (see Table S1).

The stated uncertainties of the $k_{1 \mathrm{a}}$ values in the low temperature range (Table 2) originate from linear fits to the data and are somewhat smaller than the uncertainties of the $k_{1 \mathrm{a}}$ values in the intermediate temperature range (Table 3), where the bi-exponential expression described above is fitted to the data and the stated uncertainties originate from using an error propagation method and eqn (E1). The stated uncertainties of the $k_{-1 \text { a }}$ values in the intermediate temperature range (Table 3) are obtained using an error propagation method and eqn (E2).

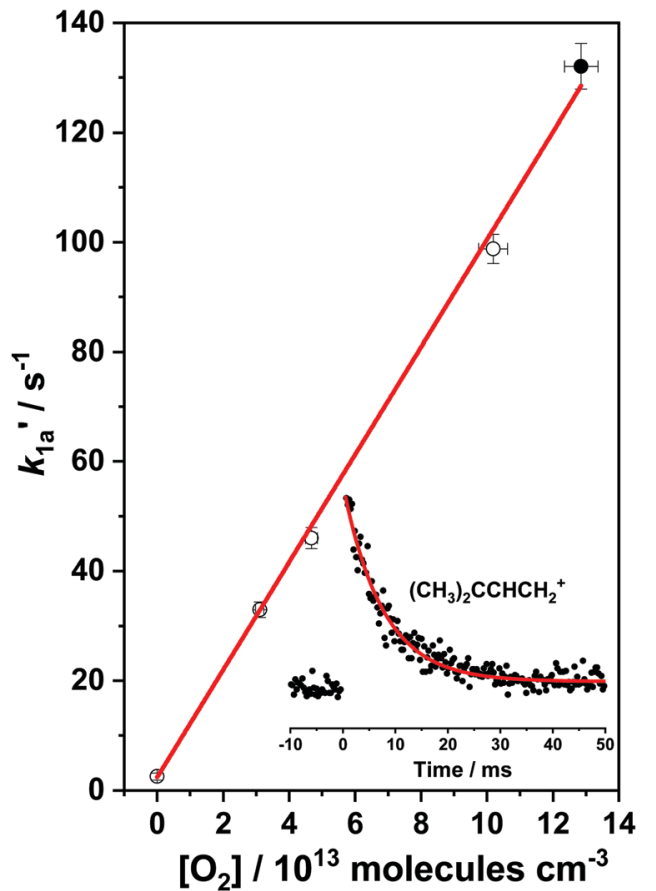

Fig. $3 \mathrm{~A}$ bimolecular plot of the $\left(\mathrm{CH}_{3}\right)_{2} \mathrm{CCHCH}_{2}+\mathrm{O}_{2} \rightarrow$ $\left(\mathrm{CH}_{3}\right)_{2} \mathrm{CCHCH}_{2} \mathrm{OO}$ association reaction (1a) measured at $T=298 \mathrm{~K}$ and $P=1.2$ Torr. A typical $\left(\mathrm{CH}_{3}\right)_{2} \mathrm{CCHCH}_{2}$ radical decay profile $\left(k_{1 \mathrm{a}}^{\prime}=132.1 \pm 4.2 \mathrm{~s}^{-1}\right.$, filled circle) for reaction (1a) is shown on the lower right corner of the plot. Statistical uncertainties shown are $1 \sigma$.

The uncertainties of the $k_{-1 \mathrm{a}}$ values are larger than those of the $k_{1 \mathrm{a}}$ values.

The overall uncertainty (accuracy) of the $k_{1 \mathrm{a}}$ values presented in Table 2 is estimated to be about $\pm 25 \%$. This estimation is composed of several sources of uncertainties. The above discussed fitting uncertainties are the single most important sources, while uncertainties to determine reactant concentrations and uncertainties in measuring temperature and pressure of the reaction zone also play a role. Overall uncertainties of the $k_{1 \mathrm{a}}$ and $k_{-1 \mathrm{a}}$ values in the intermediate temperature range are difficult to estimate.

\section{High temperature range}

Once the temperature is increased well above the intermediate temperature range, a new, considerably slower reaction channel appears to open for the $\left(\mathrm{CH}_{3}\right)_{2} \mathrm{CCHCH}_{2}+\mathrm{O}_{2}$ reaction, becoming measurable at about $500 \mathrm{~K}$ with the current apparatus. Bimolecular rate coefficients of the $\left(\mathrm{CH}_{3}\right)_{2} \mathrm{CCHCH}_{2}+\mathrm{O}_{2}$ reaction, $k_{1 \mathrm{~b}}$, were then measured over a temperature range of 500-660 K. The upper limit of $660 \mathrm{~K}$ temperature originates from the thermal stability of the $\left(\mathrm{CH}_{3}\right)_{2} \mathrm{CCHCH}_{2} \mathrm{Br}$ radical precursor in the reactor. A bimolecular plot obtained for reaction (1b) is shown in Fig. 4. The measured bimolecular rate coefficients of reaction (1b) in the temperature range 500-660 $\mathrm{K}$ are given in Table 4 . The values of $k_{1 \mathrm{~b}}$ appear to be independent of total pressure.

Measuring kinetics as slow as reaction (1b) with $k_{1 \mathrm{~b}} \approx 3-5 \times$ $10^{-15} \mathrm{~cm}^{3}$ molecule ${ }^{-1} \mathrm{~s}^{-1}$ in this work requires significant amounts of $\mathrm{O}_{2}(<51 \%$ of the total reaction mixture) to be 
Table 2 The experimental conditions and results of the low temperature range kinetics measurements for reaction (1a). ${ }^{a}$ Statistical uncertainties shown are $1 \sigma$

\begin{tabular}{llccccccc}
\hline$T(\mathrm{~K})$ & $P_{\mathrm{He}}(\mathrm{Torr})$ & {$[\mathrm{He}] / 10^{16}\left(\mathrm{~cm}^{-3}\right)$} & {$[\mathrm{Pr}] / 10^{12}\left(\mathrm{~cm}^{-3}\right)$} & {$\left[\mathrm{O}_{2}\right] / 10^{13}\left(\mathrm{~cm}^{-3}\right)$} & $k_{1 \mathrm{a}}^{\prime}\left(\mathrm{s}^{-1}\right)$ & $k_{\mathrm{wall}}^{(\mathrm{R})}{ }^{b}\left(\mathrm{~s}^{-1}\right)$ & $k_{\mathrm{wall}}^{(\mathrm{R})}\left(\mathrm{s}^{-1}\right)$ & $k_{1 \mathrm{a}} / 10^{-12}\left(\mathrm{~cm}^{3} \mathrm{molecule}^{-1} \mathrm{~s}^{-1}\right)$ \\
\hline 238 & 0.22 & 0.89 & 0.30 & $2.32-6.81$ & $47.9-119.2$ & $5.5 \pm 0.8$ & $5.5 \pm 1.5$ & $1.70 \pm 0.09$ \\
238 & 0.40 & 1.62 & 0.27 & $1.45-4.65$ & $38.2-94.3$ & $5.1 \pm 0.9$ & $5.5 \pm 1.1$ & $2.06 \pm 0.08$ \\
238 & 0.81 & 3.29 & 0.25 & $0.95-3.01$ & $33.2-79.3$ & $4.0 \pm 0.6$ & $4.2 \pm 0.7$ & $2.56 \pm 0.09$ \\
$238^{d}$ & 2.39 & 9.70 & 1.87 & $2.68-5.13$ & $109.6-167.8$ & $19.7 \pm 1.2$ & $19.8 \pm 0.9$ & $2.97 \pm 0.13$ \\
$238^{d}$ & 3.66 & 14.85 & 2.99 & $2.31-5.33$ & $120.3-202.1$ & $21.8 \pm 1.2$ & $22.4 \pm 2.7$ & $3.55 \pm 0.16$ \\
& & & & & & & \\
268 & 0.20 & 0.72 & 0.25 & $4.11-15.06$ & $43.6-129.0$ & $4.1 \pm 0.8$ & $4.3 \pm 0.8$ & $0.85 \pm 0.03$ \\
268 & 0.40 & 1.44 & 0.40 & $1.63-6.82$ & $19.5-76.1$ & $2.2 \pm 0.9$ & $2.1 \pm 0.4$ & $1.07 \pm 0.02$ \\
268 & 0.81 & 2.92 & 0.39 & $1.11-4.96$ & $25.2-79.9$ & $3.5 \pm 0.7$ & $3.5 \pm 0.7$ & $1.54 \pm 0.06$ \\
$268^{e}$ & 1.21 & 4.36 & 19.4 & $4.84-10.46$ & $80.3-184.0$ & $8.8 \pm 2.6$ & $8.5 \pm 2.1$ & $1.62 \pm 0.09$ \\
$268^{d}$ & 2.68 & 9.66 & 3.03 & $2.16-8.36$ & $69.5-185.7$ & $19.8 \pm 1.2$ & $21.9 \pm 3.6$ & $1.97 \pm 0.11$ \\
$268^{d}$ & 4.12 & 14.85 & 3.06 & $2.55-6.06$ & $86.0-160.3$ & $24.3 \pm 1.3$ & $24.2 \pm 3.0$ & $2.21 \pm 0.12$ \\
& & & & & & & \\
298 & 0.31 & 1.00 & 0.35 & $4.28-12.52$ & $17.1-60.2$ & $2.8 \pm 0.7$ & $2.5 \pm 0.8$ & $0.45 \pm 0.02$ \\
298 & 0.60 & 1.94 & 0.32 & $2.82-12.65$ & $24.0-91.7$ & $4.4 \pm 0.7$ & $4.4 \pm 0.7$ & $0.67 \pm 0.02$ \\
298 & 1.20 & 3.89 & 0.32 & $3.11-12.85$ & $33.0-132.1$ & $2.5 \pm 0.6$ & $2.4 \pm 0.6$ & $0.97 \pm 0.02$ \\
$298^{e}$ & 1.20 & 3.89 & 16.9 & $4.55-12.28$ & $53.4-134.2$ & $3.7 \pm 1.9$ & $3.8 \pm 0.7$ & $1.02 \pm 0.02$ \\
$298^{d}$ & 2.99 & 9.69 & 0.84 & $3.63-25.91$ & $74.9-297.6$ & $17.4 \pm 1.0$ & $18.4 \pm 2.2$ & $1.19 \pm 0.08$ \\
$298^{d}$ & 4.57 & 14.81 & 1.68 & $4.25-11.33$ & $81.1-164.7$ & $15.8 \pm 0.7$ & $16.4 \pm 2.1$ & $1.40 \pm 0.06$
\end{tabular}

${ }^{a}$ Xe-lamp with a sapphire window was used for detection as well as stainless steel reactor (i.d. $=1.7 \mathrm{~cm}$ ) with halocarbon wax coating, unless otherwise stated. ${ }^{b}$ Average of the measured wall rates for the $\left(\mathrm{CH}_{3}\right)_{2} \mathrm{CCHCH}_{2}$ radical. ${ }^{c}$ Wall rates determined from the linear fit $y$-axis intercepts of the bimolecular plots for reaction (1a). ${ }^{d}$ Stainless steel reactor (i.d. $=0.8 \mathrm{~cm}$ ) with halocarbon wax coating. ${ }^{e} 1$-Chloro-3-methyl-2-butene precursor was used for the production of $\left(\mathrm{CH}_{3}\right)_{2} \mathrm{CCHCH}_{2}$ radical utilizing pyrex-glass reactor (i.d. = $1.65 \mathrm{~cm}$ ) with halocarbon wax coating.

Table 3 The experimental conditions and results of the intermediate temperature range measurements for reaction $(1 a,-1 a) .{ }^{a}$ Statistical uncertainties shown are $1 \sigma$

\begin{tabular}{|c|c|c|c|c|c|c|c|c|}
\hline$T(\mathrm{~K})$ & $P_{\mathrm{He}}$ (Torr) & {$[\mathrm{He}] / 10^{16}\left(\mathrm{~cm}^{-3}\right)$} & {$\left[\mathrm{O}_{2}\right] / 10^{14}\left(\mathrm{~cm}^{-3}\right)$} & $k_{\text {wall }}^{(\mathrm{R})}\left(\mathrm{s}^{-1}\right)$ & $k_{\mathrm{irr} .}^{(\mathrm{ROO}) c}\left(\mathrm{~s}^{-1}\right)$ & $k_{1 \mathrm{a}} / 10^{-14}\left(\mathrm{~cm}^{3}\right.$ molecule $\left.{ }^{-1} \mathrm{~s}^{-1}\right)$ & $k_{-1 \mathrm{a}}\left(\mathrm{s}^{-1}\right)$ & $\ln \left(K_{e q}\right)^{d}$ \\
\hline 325 & 0.86 & 2.56 & 2.99 & $13.8 \pm 0.3$ & $15.4 \pm 1.5$ & $48.7 \pm 6.4$ & $15.0 \pm 4.7$ & $13.49 \pm 0.34$ \\
\hline 325 & 0.86 & 2.56 & 4.83 & $14.0 \pm 0.3$ & $18.1 \pm 1.8$ & $44.8 \pm 5.9$ & $15.6 \pm 6.4$ & $13.37 \pm 0.43$ \\
\hline 330 & 0.88 & 2.58 & 5.37 & $14.6 \pm 0.3$ & $18.8 \pm 2.2$ & $43.0 \pm 5.6$ & $21.7 \pm 10.3$ & $12.98 \pm 0.49$ \\
\hline 335 & 0.90 & 2.59 & 4.36 & $12.3 \pm 0.2$ & $11.8 \pm 1.1$ & $35.8 \pm 4.5$ & $24.4 \pm 5.2$ & $12.67 \pm 0.25$ \\
\hline 337 & 0.90 & 2.58 & 4.88 & $13.5 \pm 0.3$ & $15.7 \pm 1.4$ & $35.1 \pm 4.5$ & $33.3 \pm 8.2$ & $12.33 \pm 0.28$ \\
\hline 338 & 0.91 & 2.60 & 5.17 & $17.7 \pm 0.3$ & $17.2 \pm 1.5$ & $34.1 \pm 4.3$ & $31.5 \pm 7.8$ & $12.35 \pm 0.28$ \\
\hline 344 & 0.92 & 2.58 & 5.01 & $15.5 \pm 0.3$ & $17.7 \pm 1.1$ & $31.1 \pm 3.9$ & $49.6 \pm 7.5$ & $11.79 \pm 0.20$ \\
\hline 348 & 0.94 & 2.61 & 5.35 & $15.0 \pm 0.5$ & $16.5 \pm 1.1$ & $26.0 \pm 3.2$ & $56.7 \pm 7.8$ & $11.47 \pm 0.19$ \\
\hline 353 & 0.96 & 2.63 & 5.73 & $13.2 \pm 0.5$ & $20.0 \pm 4.4$ & $19.5 \pm 3.3$ & $63.2 \pm 25.7$ & $11.05 \pm 0.44$ \\
\hline 356 & 0.96 & 2.60 & 5.22 & $12.9 \pm 0.4$ & $19.5 \pm 1.8$ & $21.8 \pm 2.8$ & $98.5 \pm 13.9$ & $10.71 \pm 0.19$ \\
\hline $356^{e}$ & 1.22 & 3.31 & 7.39 & $9.8 \pm 2.1$ & $7.4 \pm 5.1$ & $24.4 \pm 11.3$ & $100.8 \pm 76.9$ & $10.80 \pm 1.09$ \\
\hline 358 & 0.97 & 2.62 & 6.37 & $14.6 \pm 0.5$ & $15.1 \pm 5.9$ & $21.7 \pm 5.7$ & $116.6 \pm 66.7$ & $10.54 \pm 0.63$ \\
\hline 361 & 0.48 & 1.28 & 5.58 & $12.6 \pm 0.3$ & $20.5 \pm 2.2$ & $15.6 \pm 3.9$ & $79.5 \pm 12.7$ & $10.58 \pm 0.30$ \\
\hline 361 & 0.96 & 2.57 & 7.17 & $13.8 \pm 0.3$ & $16.1 \pm 1.5$ & $21.3 \pm 2.8$ & $124.8 \pm 17.8$ & $10.44 \pm 0.19$ \\
\hline $361^{e}$ & 1.22 & 3.26 & 7.21 & $9.9 \pm 2.0$ & $7.9 \pm 4.8$ & $18.2 \pm 8.1$ & $116.1 \pm 85.4$ & $10.36 \pm 1.02$ \\
\hline $361^{f}$ & 3.61 & 9.66 & 6.57 & $15.9 \pm 0.9$ & $33.1 \pm 14.9$ & $13.5 \pm 4.1$ & $103.4 \pm 67.8$ & $10.17 \pm 0.72$ \\
\hline $361^{f}$ & 5.58 & 14.93 & 4.72 & $17.5 \pm 1.1$ & $39.6 \pm 21.2$ & $19.5 \pm 7.1$ & $128.5 \pm 95.0$ & $10.32 \pm 0.82$ \\
\hline 362 & 0.97 & 2.59 & 5.20 & $12.6 \pm 0.3$ & $21.4 \pm 2.8$ & $22.3 \pm 3.3$ & $153.7 \pm 25.7$ & $10.27 \pm 0.22$ \\
\hline 367 & 0.71 & 1.87 & 6.45 & $13.3 \pm 0.5$ & $19.2 \pm 4.4$ & $17.7 \pm 3.9$ & $167.7 \pm 44.6$ & $9.95 \pm 0.35$ \\
\hline 373 & 0.76 & 1.97 & 4.66 & $14.2 \pm 0.4$ & $19.2 \pm 5.9$ & $21.7 \pm 5.7$ & $264.8 \pm 71.0$ & $9.67 \pm 0.38$ \\
\hline 373 & 1.21 & 3.13 & 6.48 & $12.4 \pm 0.5$ & $20.8 \pm 6.0$ & $17.5 \pm 3.9$ & $282.2 \pm 75.3$ & $9.40 \pm 0.35$ \\
\hline
\end{tabular}

${ }^{a}$ Xe-lamp with a sapphire window was used for detection as well as Pyrex-glass reactor (i.d. $\left.=1.65 \mathrm{~cm}\right)$ with polydimethylsiloxane (PDMS) coating, unless otherwise stated. ${ }^{b}$ Average of the measured wall rates for the $\left(\mathrm{CH}_{3}\right)_{2} \mathrm{CCHCH}_{2}$ radical. ${ }^{c}$ Rate coefficients for irreversible first-order decay processes of ROO adducts, determined from the bi-exponential fit performed to the observed $\left(\mathrm{CH}_{3}\right)_{2} \mathrm{CCHCH}_{2}$ radical decay profiles. ${ }^{d}$ Natural logarithmic of the measured $K_{\text {eq }}$ values. ${ }^{e}$ 1-Chloro-3-methyl-2-butene precursor was used for the production of the $\left(\mathrm{CH}_{3}\right)_{2} \mathrm{CCHCH}_{2}$ radical as well as Pyrex-glass reactor (i.d. $=1.65 \mathrm{~cm}$ ) with halocarbon wax coating. ${ }^{f}$ Stainless steel reactor $($ i.d. $=0.8 \mathrm{~cm}$ ) with halocarbon wax coating.

added to the reaction mixture. This results in high total pressure in the reaction zone $\left(P_{\text {total }}<7.8\right.$ Torr $)$ and high oxygen content of the reaction mixture, which altogether causes high pressures in the vacuum chamber containing the quadrupole mass spectrometer $\left(P_{\mathrm{QMS}-\text { chamber }}\right)$. In fact, conditions (i.e. $\left.P_{\mathrm{QMS}-\mathrm{chamber}}\right)$ of the kinetic measurements of reaction $(1 \mathrm{~b})$ were at or even beyond the upper limit of pressure that our PIMS setup can tolerate. In addition, at $T>500 \mathrm{~K}$, presumably heterogeneous wall-effects started to have an influence on the measured $k_{1 \mathrm{~b}}^{\prime}$ values, causing some additional uncertainty on the respective $k_{1 \mathrm{~b}}$ values. There is some more discussion on this in the ESI $\dagger$ (see Fig. S2). Taking into account the abovementioned 


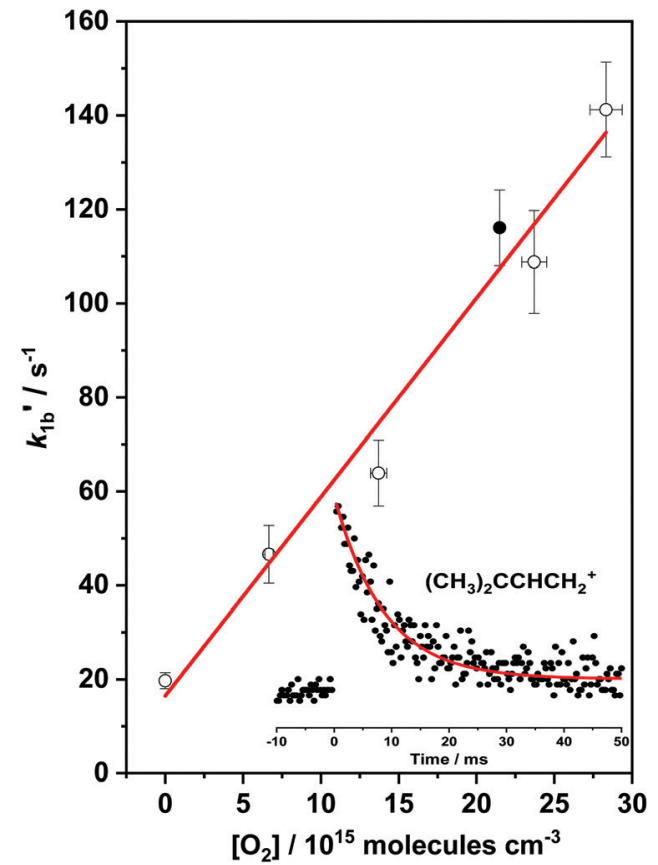

Fig. 4 A bimolecular plot for $\left(\mathrm{CH}_{3}\right)_{2} \mathrm{CCHCH}_{2}+\mathrm{O}_{2} \rightarrow$ products reaction (1b) measured at $T=550 \mathrm{~K}$ and $P=2.92$ Torr. The lower right corner of the plot presents the $\left(\mathrm{CH}_{3}\right)_{2} \mathrm{CCHCH}_{2}$ radical decay profile $\left(k_{1 \mathrm{~b}}^{\prime}=116.1 \pm 8.1 \mathrm{~s}^{-1}\right)$ under conditions of the filled circle in the plot. The uncertainties shown are $1 \sigma$.

additional uncertainty sources at $T>500 \mathrm{~K}$, including the uncertainties in the temperature and pressure measurements in the reaction zone as well as the fitting uncertainties, the overall uncertainty (=accuracy) in the $k_{1 \mathrm{~b}}$ values presented in Table 4 is estimated to be the factor of two (upper $=2 \times k_{1 \mathrm{~b}}$, lower $=0.5 \times k_{1 \mathrm{~b}}$ ).

Measurements were also conducted to detect possible products of reaction (1b). Our quantum chemistry calculations (see next section), suggest isoprene $(m / z=68)+\mathrm{HO}_{2}(m / z=33)$ to be the major product channel of reaction (1b). Our PIMS apparatus is unable to detect $\mathrm{HO}_{2}$ radical, mainly due to its high ionization energy $I E\left(\mathrm{HO}_{2}\right) \approx 11.4 \mathrm{eV} .{ }^{42}$ Utilizing $\mathrm{H}_{2}$-lamp for ionization radiation, a product formation signal was observed at $m / z=68$, see Fig. 5. However, a fast, almost immediate product formation signal at $\mathrm{m} / z=68$ was observed also in the absence of $\left[\mathrm{O}_{2}\right]$, originating, almost certainly, from the photolysis of the radical precursor $\left(\mathrm{CH}_{3}\right)_{2} \mathrm{CCHCH}_{2} \mathrm{Br}$. For this reason, two consecutive measurements were performed, the first one in the absence and the second one in the presence of $\mathrm{O}_{2}$, see Fig. 5(a). The signal without $\mathrm{O}_{2}$ was then subtracted from the signal with $\mathrm{O}_{2}$ present, giving a product formation signal at $m / z=68$ originating only from reaction (1b), see Fig. 5(b). The product formation signal at $m / z=68$ was fitted using the expression $\mathrm{I}_{t}\left(\mathrm{P}^{+}\right)=\mathrm{B}+\mathrm{I}_{0}\left(\mathrm{P}^{+}\right)\left(1-\exp \left(-k_{1 \mathrm{~b}}^{\prime}\left(\mathrm{P}^{+}\right) t\right)\right)$ where, $\mathrm{I}_{t}\left(\mathrm{P}^{+}\right)$is the temporal product ion signal and $\mathrm{I}_{0}\left(\mathrm{P}^{+}\right)$the signal value for the channel yield $\times[R]_{0}$ as $t \rightarrow \infty$. The term $k_{1 \mathrm{~b}}^{\prime}\left(\mathrm{P}^{+}\right)$was treated as an independent parameter and the fitting process returned the value $k_{1 \mathrm{~b}}^{\prime}\left(\mathrm{P}^{+}\right)=112.7 \pm 30 \mathrm{~s}^{-1}$, see the fit in Fig. 5(b). This value agrees well within the stated $1 \sigma$-uncertainty with the $k_{1 \mathrm{~b}}^{\prime}=96.5 \pm 9.5 \mathrm{~s}^{-1}$ value obtained from fitting the corresponding $\left(\mathrm{CH}_{3}\right)_{2} \mathrm{CCHCH}_{2}$ radical decay profile shown in Fig. 5(c). This shows that under utilized pseudofirst-order conditions, signal at $\mathrm{m} / z=68$ originates from reaction (1b). As already mentioned, high values of $P_{\mathrm{QMS}-\text { chamber }}$ reduces detection sensitivity of the PIMS apparatus, which is evident from the product ion signals presented in the Fig. 5.

The measured values of $k_{1 \mathrm{~b}}$ exhibit weak, positive temperature dependence. Current results show that in the temperature range of $500-660 \mathrm{~K}$, the $k_{1 \mathrm{~b}}$ values are in the range of (2.82-4.62) $\times$ $10^{-15} \mathrm{~cm}^{3}$ molecule $\mathrm{s}^{-1}$. These values are comparable to the bimolecular rate coefficient $k(753 \mathrm{~K})=3.49 \times$ $10^{-15} \mathrm{~cm}^{3}$ molecule ${ }^{-1} \mathrm{~s}^{-1}$ measured by Baldwin et al. ${ }^{23}$ for the kinetics of the $\mathrm{CH}_{2} \mathrm{CHCHCH}_{2} \mathrm{CH}_{3}+\mathrm{O}_{2} \rightarrow \mathrm{CH}_{2}=\mathrm{CHCH}=\mathrm{CHCH}_{3}$ $+\mathrm{HO}_{2}$ reaction channel at $753 \mathrm{~K}$, and about 10 times faster than an upper-limit of bimolecular rate coefficient of the $\mathrm{CH}_{3} \mathrm{CHCHCH}_{2}+\mathrm{O}_{2}$ reaction measured at $700 \mathrm{~K}$ by Knyazev et al. ${ }^{22}$ In addition, current results are an order of $10^{3}$ times faster than the bimolecular rate coefficient measured for allyl-radical + $\mathrm{O}_{2}$ reaction at a temperature of $673 \mathrm{~K}^{20}$ We are not aware of any previous measurements of bimolecular rate coefficients of the $\left(\mathrm{CH}_{3}\right)_{2} \mathrm{CCHCH}_{2}+\mathrm{O}_{2}$ reaction.

The Arrhenius plot for the forward bimolecular rate coefficients of the $\left(\mathrm{CH}_{3}\right)_{2} \mathrm{CCHCH}_{2}+\mathrm{O}_{2}$ reaction, $k_{1 \mathrm{a}}$ and $k_{1 \mathrm{~b}}$, measured in this work at the overall temperature range of (238660) $\mathrm{K}$, is presented in Fig. 6 . This plot is both striking and revealing. It shows that in both the low- and intermediate temperature ranges the $\left(\mathrm{CH}_{3}\right)_{2} \mathrm{CCHCH}_{2}+\mathrm{O}_{2}$ reaction shows negative temperature and positive pressure dependence and is faster than the allyl $+\mathrm{O}_{2}$ reaction ${ }^{19}$ but comparable to the $\mathrm{CH}_{2} \mathrm{CHCHCH}_{2} \mathrm{CH}_{3}+\mathrm{O}_{2}$ reaction $^{24}$ at $298 \mathrm{~K}$. Upon increasing temperature to about $500 \mathrm{~K}$, the rate coefficient of the $\left(\mathrm{CH}_{3}\right)_{2} \mathrm{CCHCH}_{2}+\mathrm{O}_{2}$ reaction decreases by

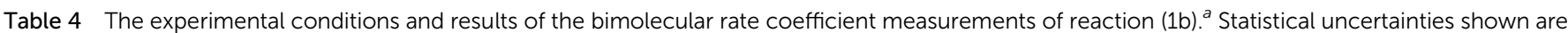
$1 \sigma$

\begin{tabular}{|c|c|c|c|c|c|c|c|c|}
\hline$T(\mathrm{~K})$ & $P_{\text {He }}($ Torr $)$ & {$[\mathrm{He}] / 10^{16}\left(\mathrm{~cm}^{-3}\right)$} & {$[\mathrm{Pr}] / 10^{12}\left(\mathrm{~cm}^{-3}\right)$} & {$\left[\mathrm{O}_{2}\right] / 10^{15}\left(\mathrm{~cm}^{-3}\right)$} & $k_{1 \mathrm{~b}}^{\prime}\left(\mathrm{s}^{-1}\right)$ & $k_{\mathrm{wall}}^{(\mathrm{R}) b}\left(\mathrm{~s}^{-1}\right)$ & $k_{\mathrm{wall}}^{(\mathrm{R}) c}\left(\mathrm{~s}^{-1}\right)$ & $k_{1 \mathrm{~b}} / 10^{-15}\left(\mathrm{~cm}^{3}\right.$ molecule $\left.{ }^{-1} \mathrm{~s}^{-1}\right)$ \\
\hline 501 & 2.90 & 5.59 & 1.25 & $7.41-29.17$ & $72.8-120.1$ & $29.6 \pm 2.3$ & $33.3 \pm 4.1$ & $2.82 \pm 0.44$ \\
\hline 502 & 2.94 & 5.66 & 2.71 & $9.84-47.43$ & 82.1-185.5 & $44.6 \pm 1.9$ & $45.0 \pm 1.2$ & $3.08 \pm 0.14$ \\
\hline 550 & 2.92 & 5.13 & 1.31 & $6.66-28.32$ & $46.6-141.3$ & $19.7 \pm 1.7$ & $18.7 \pm 2.7$ & $4.23 \pm 0.35$ \\
\hline 579 & 1.83 & 3.05 & 2.48 & $3.95-7.52$ & $20.6-33.6$ & $5.2 \pm 0.4$ & $5.22 \pm 0.1$ & $3.75 \pm 0.10$ \\
\hline 660 & 5.67 & 8.30 & 4.38 & $7.26-23.28$ & $56.8-103.3$ & $9.1 \pm 1.2$ & $9.5 \pm 1.9$ & $4.62 \pm 0.43$ \\
\hline
\end{tabular}

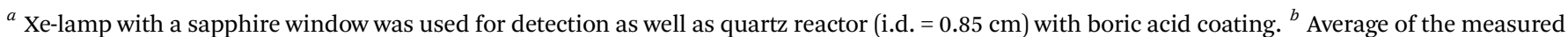
wall rates for the $\left(\mathrm{CH}_{3}\right)_{2} \mathrm{CCHCH}_{2}$ radical. ${ }^{c}$ Wall rates determined from the linear fit $y$-axis intercepts of the bimolecular plots for reaction (1b). 

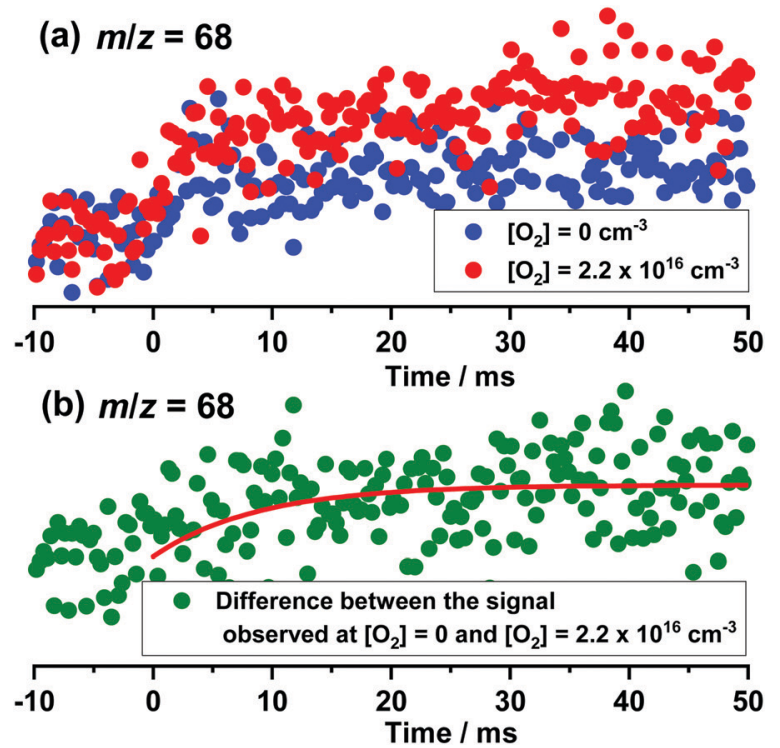

(c)

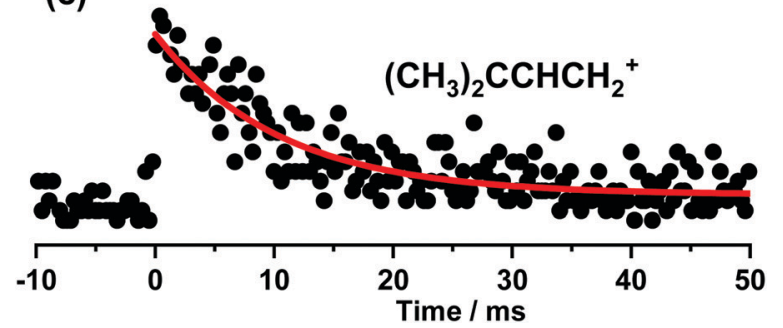

Fig. 5 The product formation and corresponding radical decay profiles for the $\left(\mathrm{CH}_{3}\right)_{2} \mathrm{CCHCH}_{2}+\mathrm{O}_{2} \rightarrow$ products reaction (1b), measured at $T=$ $501 \mathrm{~K}, P=2.9$ Torr. The top most panel (a) depicts the product ion formation signals observed at $\mathrm{m} / z=68$. The filled blue and red circles represent the product ion formation signals when $\left[\mathrm{O}_{2}\right]=0 \mathrm{~cm}^{-3}$ and $2.2 \times$ $10^{16} \mathrm{~cm}^{-3}$, respectively. The middle panel (b) shows the difference between the product ion formation signals observed at $\left[\mathrm{O}_{2}\right]=2.2 \times$ $10^{16} \mathrm{~cm}^{-3}$ and $\left[\mathrm{O}_{2}\right]=0 \mathrm{~cm}^{-3}$. The corresponding $\left(\mathrm{CH}_{3}\right)_{2} \mathrm{CCHCH}_{2}$ radical decay profile measured at $\left[\mathrm{O}_{2}\right]=2.2 \times 10^{16} \mathrm{~cm}^{-3}\left(k_{1 \mathrm{~b}}^{\prime}=96.5 \pm 9.5 \mathrm{~s}^{-1}\right)$, is shown on the bottom panel (c).

almost two orders of magnitude. The temperature dependence also changes from negative to positive and the rate coefficient becomes pressure-independent. Next, we use computational methods to better understand the kinetics and mechanism behind the observed behavior of the $\left(\mathrm{CH}_{3}\right)_{2} \mathrm{CCHCH}_{2}+\mathrm{O}_{2}$ reaction.

\section{Quantum chemistry}

The results of our quantum chemical calculations along with the geometries of the stationary points of reaction (1) are provided in the ESI $\dagger$ (Tables S2 and S3). Based on the MN15/ Def2TZVP energies, reaction channels that have barriers over $12 \mathrm{kcal} \mathrm{mol}^{-1}$ (relative to the reactants $\mathrm{R}+\mathrm{O}_{2}$ ) were omitted from additional analysis as kinetically unimportant. The remaining channels were further investigated with the ROHF-CCSD(T)/CBS method. It was discovered that the lowest energy reaction channel leads to the formation of 2-methylbut-1,3-diene (isoprene) and hydroperoxyl radical from the non-terminal

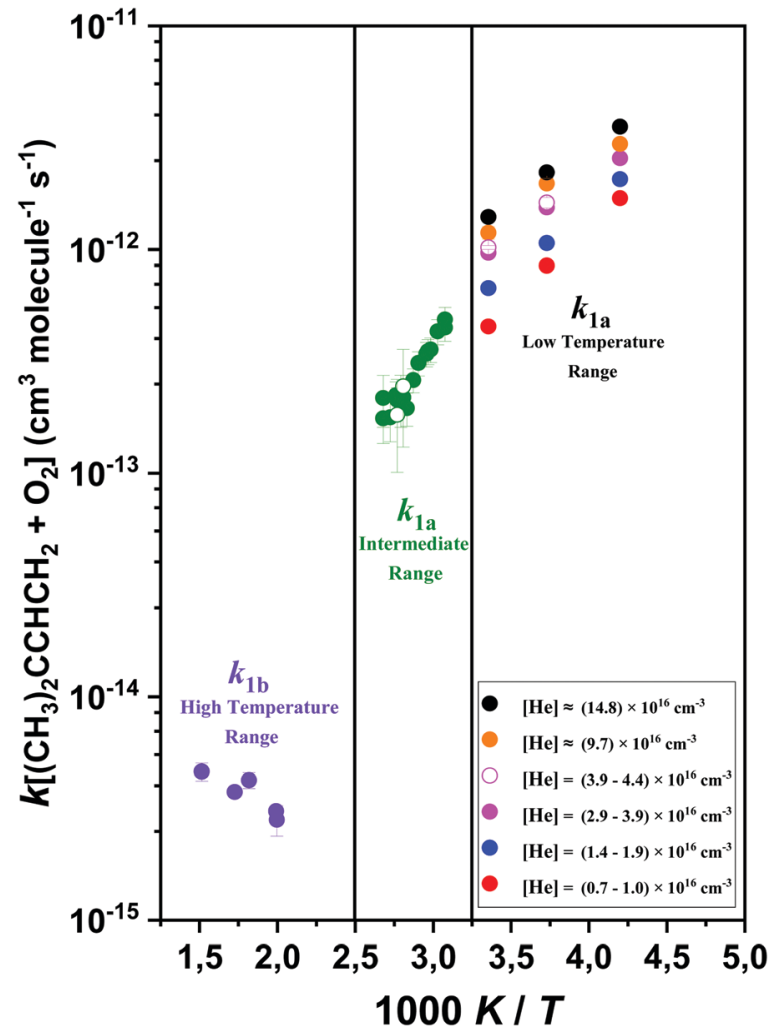

Fig. 6 An Arrhenius-type plot for the bimolecular rate coefficients of the $\left(\mathrm{CH}_{3}\right)_{2} \mathrm{CCHCH}_{2}+\mathrm{O}_{2}$ reaction (1) measured in this work. The presented dataset encompasses the employed temperature range of $238-660 \mathrm{~K}$ and bath-gas pressures 0.2-5.7 Torr, respectively. Filled and blank circles indicate the experiments conducted using brominated $\left(\left(\mathrm{CH}_{3}\right)_{2} \mathrm{CCHCH}_{2} \mathrm{Br}\right)$ and chlorinated $\left(\left(\mathrm{CH}_{3}\right)_{2} \mathrm{CCHCH}_{2} \mathrm{Cl}\right)$ photolytic precursors, respectively.

peroxyl radical $\left(\mathrm{ROO}_{(\mathrm{nt})}\right)$ by concerted elimination. At slightly higher energy appears the reaction channel that leads to the $(2 R / S)$ 3-methyl-1,2-epoxybut-3-ene and hydroxyl radical. However, both of these channels have barriers that are over $6 \mathrm{kcal} \mathrm{mol}^{-1}$ above the energy of the reactants. With barriers this high the experimental high-temperature rate coefficients would be under-predicted by several orders of magnitude. We were quite certain we had managed to locate all the important reaction channels, so we started to question the accuracy of our ROHFCCSD(T)/CBS calculations. To check whether multi-reference methods would need to be used, we recalculated the energetics of the low-energy reaction channels with the CASPT2/CBS method. Note that the T1 diagnostics were generally acceptable for the kinetically important transition state structures (below 0.03). The details of the CASPT2 calculations are given separately for each reaction channel.

\section{$\mathrm{ROO}_{(\mathrm{nt})} \rightarrow \mathrm{CH}_{2} \mathrm{C}\left(\mathrm{CH}_{3}\right) \mathrm{CHCH}_{2}+\mathrm{HO}_{2}(\mathrm{P1})$}

This is a single-step reaction where isoprene $+\mathrm{HO}_{2}$ products are formed from $\mathrm{ROO}_{(\mathrm{nt})}$ by concerted elimination (see Fig. 8). Similar to the ROHF-CCSD(T)/CBS calculations, CASPT2/CBS calculations predict this channel to have the lowest reaction barrier. ROHF-CCSD(T)/CBS calculations have a barrier of $26.3 \mathrm{kcal} \mathrm{mol}^{-1}$ above the energy of the $\mathrm{ROO}_{(\mathrm{nt})}$. CASPT2/CBS 
calculations with a 13,11 active space reduce the barrier to $22.8 \mathrm{kcal} \mathrm{mol}^{-1}$. The active space consists of the lone electron pairs of the oxygen atoms $(4,2)$, the bonding and anti-bonding $\mathrm{C}-\mathrm{O}$ and $\mathrm{O}-\mathrm{O} \sigma$ orbitals $(4,4)$, the bonding and anti-bonding $\pi$ orbitals of the $\mathrm{C}=\mathrm{C}$ bond $(2,2)$, the radical orbital on the terminal oxygen atom $(1,1)$, and the bonding and anti-bonding electron orbitals of the $\mathrm{C}-\mathrm{H}$ bond where the hydrogen is abstracted $(2,2)$. The CASPT2 barrier is $3.5 \mathrm{kcal} \mathrm{mol}^{-1}$ lower in energy than the ROHF-CCSD(T) one and is much more consistent with the experimental observations. However, we cannot rule out that this is fortuitous. Nonetheless, an energy difference this large between the CASPT2 and ROHF-CCSD(T) calculations is interesting, especially since the $\mathrm{T} 1$ diagnostic (0.029) would suggest that a single-reference approach should be appropriate. It is possible that there is a concerted elimination channel from the terminal peroxyl radical $\left(\mathrm{ROO}_{(\mathrm{t})}\right)$ that produces isoprene in its cis-form. We were, however, unable to locate the transition state structure for such a process, but we cannot rule out its existence.

\section{$\mathrm{ROO}_{(\mathrm{t})} \rightarrow \mathrm{CH}_{2} \mathrm{C}\left(\mathrm{CH}_{3}\right) \mathrm{CH}(\mathrm{O}) \mathrm{CH}_{2}+\mathrm{HO}(\mathrm{P} 3)$}

This is a two-step reaction. First $\mathrm{ROO}_{(\mathrm{t})}$ internally abstracts a hydrogen from an allylic position (see Fig. 8). Then the oxygen bonded to a carbon atom reacts with the allylic system to form a $\mathrm{C}-\mathrm{O} \sigma$-bond. As this happens, the $\mathrm{O}-\mathrm{O} \sigma$-bond is broken. The final products are $(2 R / S)$-3-methyl-1,2-epoxybut-3-ene and hydroxyl radical (P3). Two possible transition state structures were found for the hydrogen abstraction which are not rotamers. The ROHF-CCSD $(\mathrm{T})$ calculations set these transition state structures $23.9 \mathrm{kcal} \mathrm{mol}^{-1}$ and $24.0 \mathrm{kcal} \mathrm{mol}^{-1}$ above the energy of the peroxyl radical and the T1 diagnostics are acceptable, 0.024 and 0.022. For the latter step, the transition state structure is $19.6 \mathrm{kcal} \mathrm{mol}^{-1}$ above the energy of the peroxyl radical, although the T1 diagnostic is already moderately high, 0.041. The CASPT2 calculations with a 9,9 active space reduce the relative energies to 22.1 and $22.2 \mathrm{kcal} \mathrm{mol}^{-1}$ (hydrogen abstraction transition state structures) and $12.4 \mathrm{kcal} \mathrm{mol}^{-1}$ (ring-forming/OH eliminating transition state structure). The active space consists of the bonding and anti-bonding $\mathrm{C}-\mathrm{O}$ and O-O $\sigma$-orbitals $(4,4)$, the bonding and anti-bonding $\pi$-orbitals of the $\mathrm{C}=\mathrm{C}$ bond $(2,2)$, the radical orbital on the terminal oxygen atom $(1,1)$, and the bonding and anti-bonding $\mathrm{C}-\mathrm{H}$ $\sigma$-orbital of the hydrogen that is abstracted $(2,2)$. The lone pair electron orbitals of the oxygens are almost fully occupied and were left out of the active space. The hydrogen abstraction reactions are the kinetic bottleneck and the CASPT2 calculations reduce the barriers by around $2 \mathrm{kcal} \mathrm{mol}^{-1}$. However, the CASPT2 and ROHF-CCSD(T) energies are within the expected uncertainties of these methods. For the latter transition structure, CASPT2 reduces the energy by over $7 \mathrm{kcal} \mathrm{mol}^{-1}$. This is already a significant change, although somewhat expected as the $\mathrm{T} 1$ diagnostic is moderately high (0.041).

\section{Five-membered ring channel (products P4 and P6)}

This reaction channel proceeds by either the terminal $\left(\mathrm{ROO}_{(\mathrm{t})}\right)$ or non-terminal $\left(\mathrm{ROO}_{(\mathrm{nt})}\right)$ peroxy-radical reacting internally with the carbon-carbon double bond to form a fivemembered ring (see Fig. 8). The $\mathrm{O}-\mathrm{O}$ bond then breaks and either propan-2-one and 1,2-epoxyethyl P4 or methanal and 2-methyl-1,2-epoxyprop-1-yl P6 are formed. The ring-forming transition state structures have acceptable $\mathrm{T} 1$ diagnostics $(<0.03)$ and ROHF-CCSD $(\mathrm{T})$ calculations predict the barriers 27-31 kcal mol $\mathrm{m}^{-1}$ above the energy of $\mathrm{ROO}_{(\mathrm{nt})}$. Only preliminary ROHF-CCSD(T) calculations were performed for the ringbreaking transition state structures because the T1 diagnostics are above 0.05 . CASPT2 calculations reduce the relative energies of the ring-forming transition structures by $2-3 \mathrm{kcal} \mathrm{mol}^{-1}$. The CASPT2 relative energies for the ring-breaking transition state structures are $27.0 \mathrm{kcal} \mathrm{mol}^{-1} \mathrm{P} 4$ and $25.5 \mathrm{kcal} \mathrm{mol}^{-1} \mathrm{P} 6$, respectively. An active space of 7,7 was used in these calculations. The orbitals are the bonding and anti-bonding $\mathrm{O}-\mathrm{O}$ and $\mathrm{C}-\mathrm{O} \sigma$ orbitals $(4,4)$, the bonding and anti-bonding $\pi$ orbitals of the $\mathrm{C}=\mathrm{C}$ bond $(2,2)$, and the radical orbital on the terminal oxygen atom $(1,1)$. Again, we observe that CASPT2 calculations reduce the barrier heights. This reaction channel has barriers that are several kcal mol ${ }^{-1}$ higher in energy than the (P1) channel and is not expected to be kinetically important.

\section{Four-membered ring channel (products P2, P4, P6, P7)}

The peroxyl radicals can react with the double bond also to form four-membered rings, which can subsequently form products by either breaking the $\mathrm{O}-\mathrm{O}$ or the $\mathrm{C}-\mathrm{C}$ bond (see Table $\mathrm{S} 2$, ESI $\dagger$ ). In these reactions multi-reference behavior was more apparent and ROHF-CCSD(T) calculations were not carried out systematically. A 9,9 active space was chosen to explore the energetics of these reactions. The orbitals are the bonding and anti-bonding $\mathrm{O}-\mathrm{O}$ and $\mathrm{C}-\mathrm{O}$ orbitals $(4,4)$, the bonding and anti-bonding $\pi$ orbitals of the $\mathrm{C}=\mathrm{C}$ bond $(2,2)$, the radical orbital on the terminal oxygen atom $(1,1)$, and the bonding and anti-bonding orbitals of the $\mathrm{C}-\mathrm{C}$ bond that is present in the four-membered ring. As one would expect, the barriers in the four-membered ring channel are noticeably higher in energy than the barriers in the fivemembered ring channel and for this reason the four-membered ring channel is not expected to be kinetically important.

We observe that CASPT2 calculations systematically predict lower barriers in comparison to ROHF-CCSD(T) calculations. Significant reductions in barrier heights are observed even in cases where the $\mathrm{T} 1$ diagnostic suggest that a single-reference method is suitable. The obvious question is which energies should we trust? The ROHF-CCSD(T) method produces more reliable results when a single-reference approach is suitable, and for the many important transition state structures the T1 diagnostics suggest that such an approach is suitable. However, we are confident in our experimental findings, which strongly suggest that the ROHF-CCSD(T) energies (barriers) are too high and that the CASTP2 energies are more reasonable. If the CASPT2 energies are indeed more correct, it may indicate that the $\mathrm{T} 1$ diagnostic alone is a less reliable measure of the multireference character present in the studied species. Although we are more inclined to trust the CASPT2 energies, we cannot entirely rule out the possibility that the ROHF-CCSD(T) energies are reliable, in which case we have simply failed to locate 
low-energy reaction channel(s). For ME simulations, we decided to use ROHF-CCSD(T) energies for the peroxyl radicals $\left(\mathrm{ROO}_{(\mathrm{t})}, \mathrm{ROO}_{(\mathrm{nt})}\right.$ well-depths) and for the products. CASPT2 energies are used for everything else. To simplify the simulations, we left out all reaction channels with a barrier higher than $8 \mathrm{kcal} \mathrm{mol}^{-1}$ above the energy of the reactants.

\section{ME simulation results}

As discussed in the experimental section, under conditions where kinetic equilibrium is established (e.g. reactions (1a) and $(-1 \mathrm{a})$ ), a decay profile of a resonance-stabilized radical with two non-similar resonance structures follows, in principle, a tri-exponential behavior, but can be fitted with a doubleexponential expression. This double-exponential fit yields "average" values for the forward and reverse rate coefficients and can be used to compute an "average" equilibrium constant value. Such results of the double-exponential fits to the measured radical decays at an intermediate temperature range are given in Table 3. However, our quantum chemistry calculations revealed that the $\mathrm{ROO}_{(\mathrm{t})}$ well depth is around $2.5 \mathrm{kcal} \mathrm{mol}^{-1}$ more shallow than the $\mathrm{ROO}_{(\mathrm{nt})}$ well depth. Simulations further revealed that at $325 \mathrm{~K}$, the lowest temperature of our equilibrium constant measurements, the equilibrium population of the $\mathrm{ROO}_{(\mathrm{t})}$ is already below $3 \%$ (i.e. $\left[\mathrm{ROO}_{(\mathrm{t})}\right] /\left(\left[\mathrm{ROO}_{(\mathrm{t})}\right]+\left[\mathrm{ROO}_{(\mathrm{nt})}\right]\right)<$ 0.03). Therefore, the kinetic traces measured in the intermediate temperature range (325-373 K) can be described almost entirely by the kinetic behavior of the $\mathrm{R}+\mathrm{O}_{2} \rightleftharpoons \mathrm{ROO}_{(\mathrm{nt})}$ reaction channel.

In our modeling effort, we first used our experimental lowand intermediate-temperature kinetic data to obtain the optimal values for the ROO well-depths as well as for both the exponential-down collision energy transfer (E9) and modified Arrhenius expression (E8) parameters. For the barrierless association reaction channels $\mathrm{R}+\mathrm{O}_{2} \rightleftharpoons \mathrm{ROO}_{(\mathrm{t})}$ and $\mathrm{R}+\mathrm{O}_{2} \rightleftharpoons$ $\mathrm{ROO}_{(\mathrm{nt})}$, MESMER returned the following modified Arrhenius expressions at the high-pressure limit $\left(E_{\mathrm{a}}\right.$ in (E8) was set $\left.=0\right)$ : $k_{\infty}^{1(t)}(T)=1.17 \times 10^{-12}\left(\frac{T}{300 \mathrm{~K}}\right)^{-1.06} \mathrm{~cm}^{3}$ molecule $^{-1} \mathrm{~s}^{-1}$ and

$k_{\infty}^{1(\mathrm{nt})}(T)=2.34 \times 10^{-12}\left(\frac{T}{300 \mathrm{~K}}\right)^{-1.04} \mathrm{~cm}^{3}$ molecule ${ }^{-1} \mathrm{~s}^{-1}$,

respectively. The optimized $\left\langle\Delta E_{\text {down }}\right\rangle$ parameters are presented by the following expression: $\left\langle\Delta E_{\text {down }}\right\rangle=166\left(\frac{T}{300 \mathrm{~K}}\right)^{0.1} \mathrm{~cm}^{-1}$. See also Table 5 for these values. For helium bath-gas, the obtained $\left\langle\Delta E_{\text {down }}\right\rangle$ parameters (i.e. $\left\langle\Delta E_{\text {down,ref }}\right\rangle=166 \mathrm{~cm}^{-1}, n=$ $0.1)$, lies within their typical limits. ${ }^{38}$

In the fitting process, the energy difference between $\mathrm{ROO}_{(\mathrm{nt})}$ and $\mathrm{ROO}_{(\mathrm{t})}$ well-depths was constrained to remain equal to the energy difference obtained from ROHF-CCSD(T)/CBS calculations. The fitted ROO well-depths are $0.72 \mathrm{kcal} \mathrm{mol}^{-1}$ shallower than the computed ones, but are within estimated computational uncertainty $\left(\sim 1 \mathrm{kcal} \mathrm{mol}^{-1}\right)$.

As shown in Fig. 7, the measured values of average $\ln \left(K_{\text {eq }}\right)$ at the intermediate temperature range are plotted alongside the calculated channel-specific $\ln \left(K_{\text {eq }}\right)$ values of reaction channels $\mathrm{R}+\mathrm{O}_{2} \rightleftharpoons \mathrm{ROO}_{(\mathrm{t})}$ and $\mathrm{R}+\mathrm{O}_{2} \rightleftharpoons \mathrm{ROO}_{(\mathrm{nt})}$. For a given temperature range, MESMER uses NASA-polynomials for generating the temperature dependent standard thermodynamic quantities, such as standard enthalpy $\left(H^{\circ}\right)_{\mathrm{T}}$, entropy $\left(S^{\circ}\right)_{\mathrm{T}}$ and Gibbs free energy $\left(G^{\circ}\right)_{\mathrm{T}}$, for different reaction species. These standard thermodynamic quantities are then used for calculating the $\ln \left(K_{\mathrm{eq}}\right)$ values for each reaction channel independently. The thermodynamic MESMER output file contains the standard thermodynamic quantities of a particular species in their zero-point energy corrected form e.g. $\left(G_{\text {corr }}^{\circ}\right)_{T}=$ $\left(G^{\circ}\right)_{T}-\left(G^{\circ}\right)_{0 \mathrm{~K}}$. This enables us to locate the changes in the calculated channel specific $\ln \left(K_{\text {eq }}\right)$ values with respect to the fitted ROO well-depths. Interestingly, the more shallow $\mathrm{ROO}_{(\mathrm{nt})}$ and $\mathrm{ROO}_{(\mathrm{t})}$ well-depths (by $0.72 \mathrm{kcal} \mathrm{mol}^{-1}$ each) returned by the fitting process, give the $\ln \left(K_{\text {eq }}\right)$ values for reaction channel $\mathrm{R}$ $+\mathrm{O}_{2} \rightleftharpoons \mathrm{ROO}_{(\mathrm{nt})}$ that are equivalent to the measured average $\ln \left(K_{\text {eq }}\right)$ values, see Fig. 7. This strongly suggests that the kinetic traces measured in the intermediate temperature range are almost entirely due to the $\mathrm{R}+\mathrm{O}_{2} \rightleftharpoons \mathrm{ROO}_{(\mathrm{nt})}$ reaction channel.

Incorporating $0.72 \mathrm{kcal} \mathrm{mol}^{-1}$ (shallower) correction to the $\mathrm{ROO}_{(\mathrm{nt})}$ and $\mathrm{ROO}_{(\mathrm{t})}$ well-depths provides the standard reaction enthalpies $\left(\Delta H_{\mathrm{r}}^{\circ}\right)_{298}$ for reaction channels $\mathrm{R}+\mathrm{O}_{2} \rightleftharpoons \mathrm{ROO}_{(\mathrm{t})}$ and $\mathrm{R}+\mathrm{O}_{2} \rightleftharpoons \mathrm{ROO}_{(\mathrm{nt})}$ to be (-17.1) kcal mol${ }^{-1}$ and $(-20.0) \mathrm{kcal} \mathrm{mol}^{-1}$, respectively.

The potential energy profile utilized in the ME simulations of reaction (1), already including the $0.72 \mathrm{kcal} \mathrm{mol}^{-1}$ correction to the ROO well-depths, is shown in Fig. 8. The product energies are from ROHF-CCSD(T)/CBS calculations and all the other energies, apart from the ROO well-depths, are from CASPT2 calculations.

Measured bimolecular rate coefficients of reaction (1a) at three temperatures along with the results of constrained $\mathrm{ME}$ simulations performed over a wide pressure range are shown in Fig. 9. As can be seen, a reasonably good agreement with the experimental results is obtained.

While the constrained ME model is able to reproduce the experimental kinetic data in the low-temperature range, the simulated bimolecular rate coefficients in the high-temperature range are a factor of 5-9 times lower than the respective experimental $k_{1 \mathrm{~b}}$ values. To remedy this, we lowered the barrier height of transition state (TS1NTP1) associated with the kinetically most dominant channel $\mathrm{R}+\mathrm{O}_{2} \rightarrow$ isoprene $+\mathrm{HO}_{2}$

Table 5 The MESMER optimized $\left\langle\Delta E_{\text {down }}\right\rangle$ and the modified Arrhenius equation parameters at the high-pressure limit for the reaction channels $\mathrm{R}+\mathrm{O}_{2} \rightleftharpoons \mathrm{ROO}_{(\mathrm{t})}$ and $\mathrm{R}+\mathrm{O}_{2} \rightleftharpoons \mathrm{ROO}_{(\mathrm{nt})}$

\begin{tabular}{|c|c|c|c|c|c|}
\hline $\begin{array}{l}\left\langle\Delta E_{\text {down,ref }}\right\rangle \\
\left(\mathrm{cm}^{-1}\right)\end{array}$ & $n$ & $\underset{\left(\mathrm{cm}^{3} \text { molecule }^{-1} \mathrm{~s}^{-1}\right)}{\stackrel{A}{\rightleftharpoons} \mathrm{ROO}_{(\mathrm{t})}}$ & $\underset{\left(\mathrm{cm}^{3} \text { molecule }^{-1} \mathrm{~S}^{-1}\right)}{\stackrel{A}{\rightleftharpoons} \mathrm{ROO}_{(\mathrm{Ot})}}$ & $\mathrm{R}+\mathrm{O}_{2} \stackrel{m}{\rightleftharpoons} \mathrm{ROO}_{(\mathrm{t})}$ & $\mathrm{R}+\mathrm{O}_{2} \stackrel{m}{\rightleftharpoons} \mathrm{ROO}_{(\mathrm{nt})}$ \\
\hline 166 & 0.1 & $1.17 \times 10^{-12}$ & $2.34 \times 10^{-12}$ & $(-1.06)$ & $(-1.04)$ \\
\hline
\end{tabular}




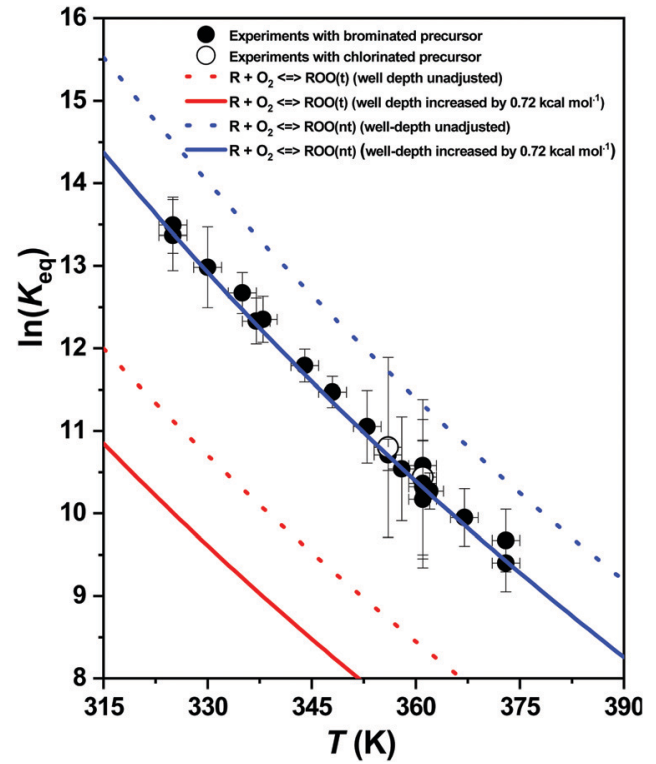

Fig. 7 The $\ln \left(K_{\text {eq }}\right)$ values of the $\mathrm{R}+\mathrm{O}_{2} \rightleftharpoons \mathrm{ROO}$ reactions $(1 \mathrm{a},-1 \mathrm{a}), \mathrm{R}=$ $\left(\mathrm{CH}_{3}\right)_{2} \mathrm{CCHCH}_{2}$, plotted as a function of temperature. Experimental results are given as symbols and computational MESMER results as lines. Filled and blank circles indicate the experiments conducted with brominated $\left(\left(\mathrm{CH}_{3}\right)_{2} \mathrm{CCHCH}_{2} \mathrm{Br}\right)$ and chlorinated $\left(\left(\mathrm{CH}_{3}\right)_{2} \mathrm{CCHCH}_{2} \mathrm{Cl}\right)$ precursors, respectively.

by $\sim 2.2 \mathrm{kcal} \mathrm{mol}^{-1}$. This adjustment is within the expected uncertainty of the CASPTP2/CBS calculations.

During our ME simulations, we discovered that under most pressure conditions there is a one-to-one correspondence between an eigenvalue $\lambda_{1}$ and the high-temperature bimolecular rate coefficients $k_{1 \mathrm{~b}}$ at $T>450 \mathrm{~K}$. This correspondence was checked at different temperatures and pressures by manually performing single-exponential fits to simulated decay profiles. Similarly, we also observed that an eigenvalue $\lambda_{2}$ corresponds to the bimolecular rate coefficients measured in the low temperature range $(T<300 \mathrm{~K})$. The pressure and temperature dependent behavior of $\lambda_{1}$ and $\lambda_{2}$ is illustrated in Fig. 10. Interestingly, under extremely low pressure conditions $\left(P \sim 1 \times 10^{-7}\right.$ bar $)$ there is a nearly seamless transition from $\lambda_{1}$ to $\lambda_{2}$ upon increasing temperature. Above this pressure, there exists a narrow transition region $(\sim 300-450 \mathrm{~K})$ where the kinetic behavior of the system cannot be described by a single eigenvalue. In this region multidimensional decays are observed.

We multiply $-\lambda_{1} /\left[\mathrm{O}_{2}\right]$ with the calculated branching ratios of different product channels to obtain channel-specific bimolecular rate coefficients at $T>450 \mathrm{~K}$. Arrhenius fits were then performed to obtain the results in a form that is usable in autoignition and combustion models. The channel specific Arrhenius fit parameters are reported in Table 6.

The Arrhenius expressions of Table 6 fit closely the results of ME simulations of bimolecular reaction channels leading to products $\mathrm{P} 1, \mathrm{P} 3, \mathrm{P} 4$, and $\mathrm{P} 6$, which are shown in Fig. 11(a). Among all the channels studied in this work, $\left(\mathrm{CH}_{3}\right)_{2} \mathrm{CCHCH}_{2}+$ $\mathrm{O}_{2} \rightarrow$ isoprene $+\mathrm{HO}_{2}(\mathrm{P} 1)$ is overwhelmingly the dominating one with a yield $>91 \%$ or so without any adjustment to the stationary-point energies. This corroborates our assignment of product formation signal observed at $m / z=68$ (see Fig. 5) originating from isoprene. The second most important channel is (2R/S)-3-methyl-1,2-epoxybut-3-ene $+\mathrm{OH}$ (P3) with yield $<8 \%$. In Fig. 11(b), the ME simulated $k_{1 \mathrm{~b}}$ values obtained for different channels are compared to the current experimental $k_{1 \mathrm{~b}}$ values. Clearly, an adjustment to stationary-point energy, here to TS1NTP1, is required to reach agreement with the

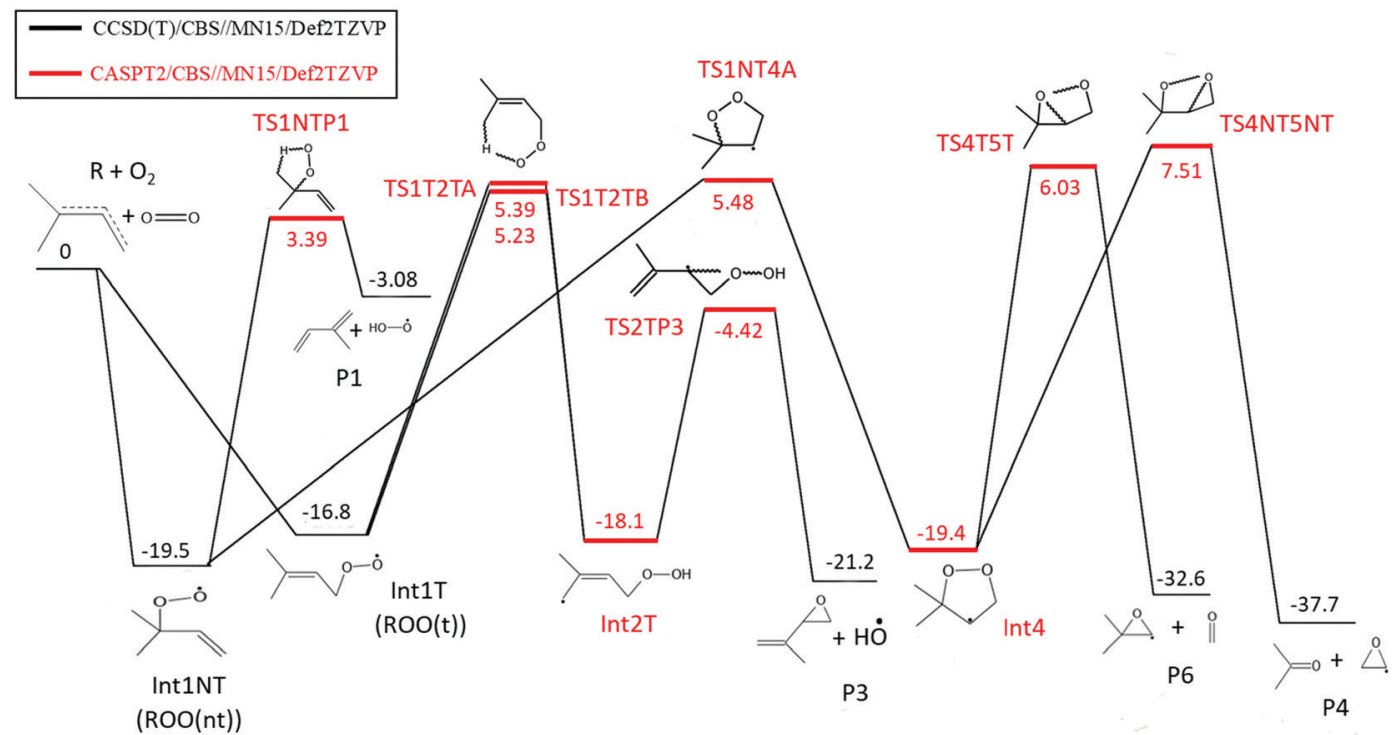

Fig. 8 The simplified potential energy profile for the $\mathrm{R}+\mathrm{O}_{2} \rightleftharpoons$ reaction $\left(\mathrm{R}=\left(\mathrm{CH}_{3}\right)_{2} \mathrm{CCHCH}_{2}\right)$ used in our ME simulations. Energies are in kcal mol ${ }^{-1}$. The reported Int1T $\left(\mathrm{ROO}_{(\mathrm{t})}\right)$ and Int1NT $\left(\mathrm{ROO}_{(\mathrm{nt})}\right)$ energies include the correction of $0.72 \mathrm{kcal} \mathrm{mol}^{-1}$. The rest of the energies are either from ROHF-CCSD(T)/ CBS//MN15/Def2TZVP or CASPT2/CBS//MN15/Def2TZVP calculations. The optimized geometries, T1 diagnostic values and single point energies of the stationary points are given in the ESI† (see Tables S2-S3). 


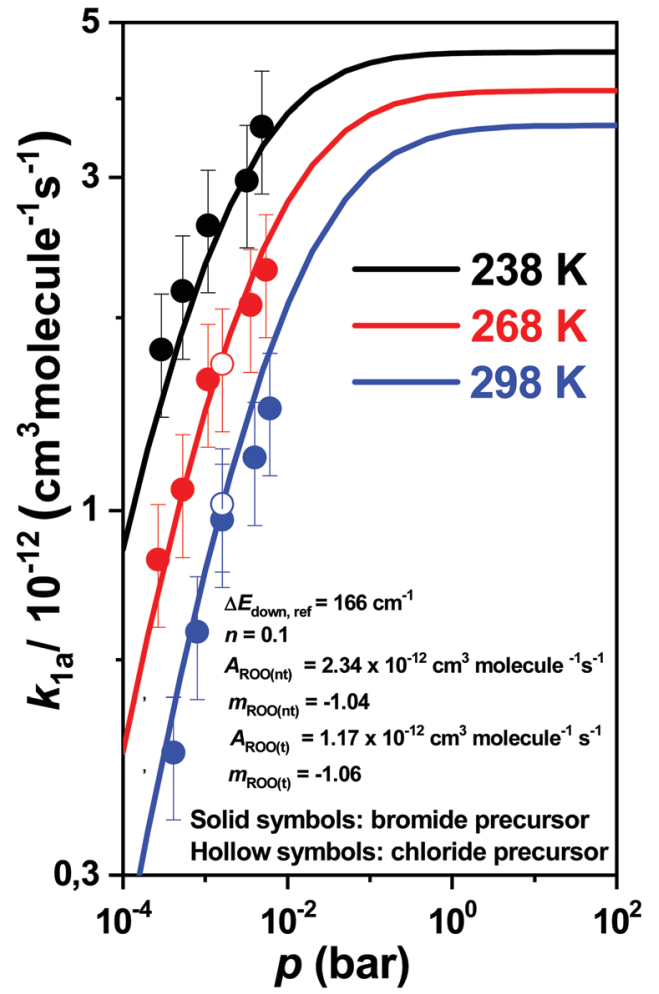

Fig. 9 The bimolecular rate coefficients of reaction (1a), $\mathrm{R}+\mathrm{O}_{2} \rightarrow$ $\mathrm{ROO}(\mathrm{t}, \mathrm{nt}), \mathrm{R}=\left(\mathrm{CH}_{3}\right)_{2} \mathrm{CCHCH}_{2}$, plotted as a function of pressure at three temperatures. The symbols depict the experimental results and the lines show the results of ME simulations. The optimized modified Arrhenius equation parameters at the high-pressure limit and $\left\langle\Delta E_{\text {down }}\right\rangle$ parameters are shown on the lower right corner. Filled and blank circles indicate the experiments conducted with brominated $\left(\left(\mathrm{CH}_{3}\right)_{2} \mathrm{CCHCH}_{2} \mathrm{Br}\right)$ and chlorinated $\left(\left(\mathrm{CH}_{3}\right)_{2} \mathrm{CCHCH}_{2} \mathrm{Cl}\right)$ precursors, respectively.

experimental results. Also shown in Fig. 11(b) are the bimolecular rate coefficients of the $\left(\mathrm{CH}_{3}\right)_{2} \mathrm{CCHCH}_{2}+\mathrm{O}_{2} \rightarrow$ isoprene $+\mathrm{HO}_{2}$ (P1) reaction channel used by Westbrook et al. ${ }^{16}$ in their kinetic modeling study of 2M2B oxidation. Apparently, the current ME simulated $k_{1 \mathrm{~b}}$ values obtained for the respective $\left(\mathrm{CH}_{3}\right)_{2} \mathrm{CCHCH}_{2}+$ $\mathrm{O}_{2} \rightarrow$ P1 reaction channel only intersect with the results of Westbrook et al. at around $T \sim 1600 \mathrm{~K}$, and diverge sharply for temperatures above and especially below $1600 \mathrm{~K}$. The MESMER input file $\left(\left(\mathrm{CH}_{3}\right)_{2} \mathrm{CCHCH}_{2} \times \mathrm{xml}\right)$ used for ME modeling is available in the ESI. $\dagger$

Probably the main outcome of the current, combined experimental and theoretical study of the allylic $\mathrm{C}_{5}$ radical reaction $\left(\mathrm{CH}_{3}\right)_{2} \mathrm{CCHCH}_{2}+\mathrm{O}_{2}$ is that larger $\left(>\mathrm{C}_{4}\right)$ allylic radicals seem to be more reactive with respect to $\mathrm{O}_{2}$ under low-temperature combustion (LTC) conditions $(T<1000 \mathrm{~K})$ than is currently believed. However, more work is certainly needed on oxidation kinetics of allylic radicals under LTC conditions to better understand their effects on autoignition behavior of fuel-air mixtures containing alkenes. Similar to this work, investigating oxidation kinetics of different allylic $\mathrm{C}_{5}$ (and larger) radical isomers experimentally (and theoretically) over a wide temperature range would be valuable. Also, it would be highly useful to have photolysis-initiated product studies of alkene oxidation

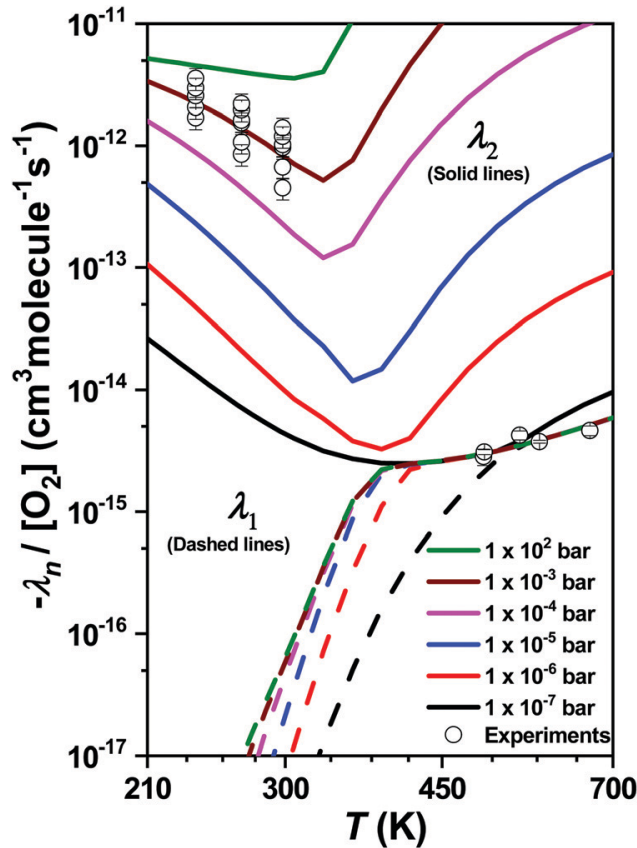

Fig. 10 The chemically significant eigenvalues $\lambda_{1}$ (dashed lines) and $\lambda_{2}$ (solid lines) plotted as a function of temperature and pressure. The symbols depict results of the measurements. $\mathrm{ROO}_{(\mathrm{t})}$ and $\mathrm{ROO}_{(\mathrm{nt})}$ well-depths were shallowed by $\sim 0.72 \mathrm{kcal} \mathrm{mol}^{-1}$ each and the barrier height for the transition state (TS1NTP1) associated with channel $\mathrm{R}+\mathrm{O}_{2} \rightarrow$ isoprene + $\mathrm{HO}_{2}$ (P1) was lowered by $\sim 2.2 \mathrm{kcal} \mathrm{mol}^{-1}$.

Table 6 Arrhenius expression parameters for different product channels of $\left(\mathrm{CH}_{3}\right)_{2} \mathrm{CCHCH}_{2}+\mathrm{O}_{2} \rightarrow$ products, reaction (1b), in the high temperature range

\begin{tabular}{|c|c|c|c|}
\hline \multirow[b]{2}{*}{$\begin{array}{l}\text { Reaction channel } \\
(T=450-2000 \mathrm{~K})\end{array}$} & \multicolumn{3}{|l|}{$k=A(T)^{m} \mathrm{e}^{-\frac{E_{\mathrm{a}}}{R T}}$} \\
\hline & $\begin{array}{c}A \\
\left(\mathrm{~cm}^{3} \text { molecule }{ }^{-1} \mathrm{~s}^{-1}\right)\end{array}$ & $m$ & $\begin{array}{c}E_{\mathrm{a}} \\
\left(\mathrm{kcal} \mathrm{mol}^{-1}\right)\end{array}$ \\
\hline \multicolumn{4}{|c|}{ TS1NTP1 lowered by $\sim 2.2 \mathrm{kcal} \mathrm{mol}^{-1}$} \\
\hline $\mathrm{R}+\mathrm{O}_{2} \rightarrow \mathrm{P} 1$ & $1.46 \times 10^{-19}$ & 1.71 & 0.78 \\
\hline \multicolumn{4}{|c|}{ Transition states unadjusted } \\
\hline $\mathrm{R}+\mathrm{O}_{2} \rightarrow \mathrm{P} 1$ & $2.87 \times 10^{-20}$ & 1.91 & 2.46 \\
\hline $\mathrm{R}+\mathrm{O}_{2} \rightarrow \mathrm{P} 3$ & $2.09 \times 10^{-28}$ & 3.76 & -2.53 \\
\hline $\mathrm{R}+\mathrm{O}_{2} \rightarrow \mathrm{P} 4$ & $3.56 \times 10^{-18}$ & 0.79 & 7.02 \\
\hline $\mathrm{R}+\mathrm{O}_{2} \rightarrow \mathrm{P} 6$ & $3.18 \times 10^{-18}$ & 0.77 & 5.51 \\
\hline
\end{tabular}

experiments available that have been performed under LTC conditions.

\section{Conclusion}

In this work, we have performed the first direct kinetic measurements of the $\left(\mathrm{CH}_{3}\right)_{2} \mathrm{CCHCH}_{2}+\mathrm{O}_{2}$ reaction over a wide temperature range $(238-660 \mathrm{~K})$ at low pressures (0.2-5.7 Torr) using photoionization mass spectrometry. Under combustion conditions, the $\left(\mathrm{CH}_{3}\right)_{2} \mathrm{CCHCH}_{2}$ radical $(\mathrm{R})$ may be produced in $\mathrm{H}-$ atom abstraction reactions from 2-methyl-2-butene $\left(\left(\mathrm{CH}_{3}\right)_{2} \mathrm{CCHCH}_{3}\right)$ or in decomposition reactions of larger olefinic fuel constituents. The resonance-stabilized $\left(\mathrm{CH}_{3}\right)_{2} \mathrm{CCHCH}_{2}$ radical has terminal 

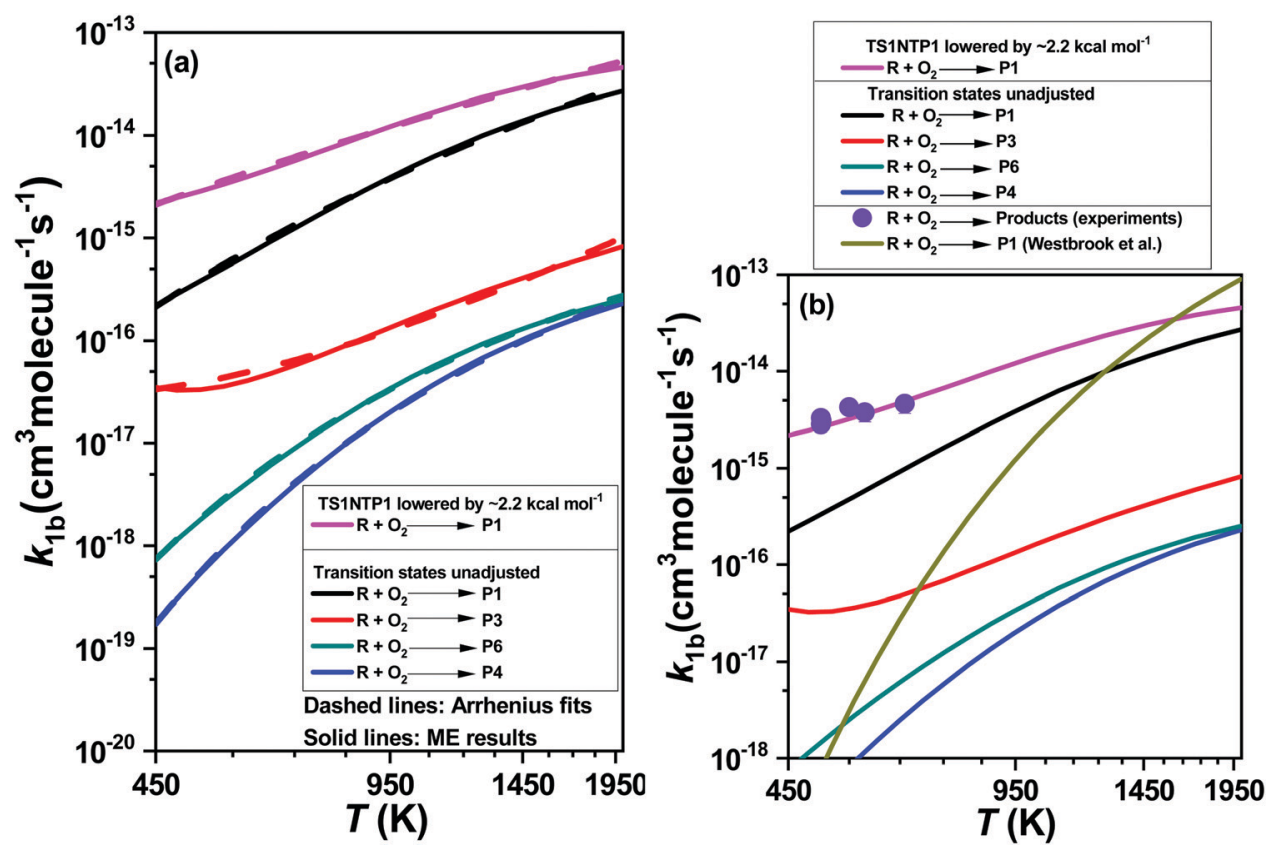

Fig. 11 The graph (a) shows the results of ME simulations of different product channels of reaction $k_{1 \mathrm{~b}}$ (solid lines) as well as their respective Arrhenius fits (dashed lines) given in Table 6 . The graph (b) depicts the same results of ME simulations as in (a), compared with our experimental $k_{1 b}$ values (symbols). The graph (b) also shows the rate-coefficients of the $\left(\mathrm{CH}_{3}\right)_{2} \mathrm{CCHCH}_{2}+\mathrm{O}_{2} \rightarrow$ isoprene $+\mathrm{HO}_{2}$ (P1) bimolecular reaction channel estimated by Westbrook et al. ${ }^{16}$ in their $2 \mathrm{M} 2 \mathrm{~B}$ oxidation study.

and non-terminal radical sites available for association with molecular oxygen $\left(\mathrm{O}_{2}\right)$, resulting in the formation of $\mathrm{ROO}_{(\mathrm{t})}$ and $\mathrm{ROO}_{(\mathrm{nt})}$ adducts, respectively. At low temperatures (238-298 K), the kinetics of reaction (1) is governed by the $\mathrm{R}+\mathrm{O}_{2} \rightarrow \mathrm{ROO}$ adduct formation, exhibiting a typical negative temperature and positive pressure dependence behavior. At the intermediate temperatures (325-373 K), kinetics of equilibrium $\mathrm{R}+\mathrm{O}_{2} \rightleftharpoons$ ROO reaction is measured and experimental equilibrium constant $\ln \left(K_{\text {eq }}\right)$ values are determined. Master equation (ME) simulations and concomitant $\operatorname{CCSD}(\mathrm{T})$ and CASPT2 potential energy profile calculations of reaction (1) were performed to support experimental observations. After making a modest adjustment to the $\mathrm{ROO}_{(\mathrm{t})}$ and $\mathrm{ROO}_{(\mathrm{nt})}$ well-depths $\left(\sim 0.7 \mathrm{kcal} \mathrm{mol}^{-1}\right.$ each), the ME model was able to reproduce the $\mathrm{R}+\mathrm{O}_{2}$ kinetics measured at low and intermediate temperatures. Interestingly, simulations reveal that the kinetics of the $\mathrm{R}+$ $\mathrm{O}_{2} \rightleftharpoons$ ROO equilibrium reaction measured at intermediate temperature ranges is almost entirely dominated by the $\mathrm{R}+$ $\mathrm{O}_{2} \rightleftharpoons \mathrm{ROO}_{(\mathrm{nt})}$ reaction channel. Probably the most important outcome of the current work was the observation and subsequent measurements of significantly faster kinetics of the $\mathrm{R}+\mathrm{O}_{2}$ reaction (1) at high temperatures than combustion models currently expect. The measured bimolecular rate coefficients $k_{1 \mathrm{~b}}=(2.8-4.6) \times 10^{-15} \mathrm{~cm}^{3}$ molecule ${ }^{-1} \mathrm{~s}^{-1}$ in the range $500-660 \mathrm{~K}$ are pressure-independent and exhibit a weak positive temperature dependence. ME simulations were also performed to calculate kinetics at high temperatures. However, without any corrections to the calculated stationary point energies, $\mathrm{ME}$ simulations of the $\mathrm{R}+\mathrm{O}_{2}$ reaction suggest about a factor of 5-9 times slower kinetics than the measured $k_{1 \mathrm{~b}}$ values.
The ME simulations suggest isoprene (2-methylbut-1,3-diene) + $\mathrm{HO}_{2}$ to be the major product channel of the $\left(\mathrm{CH}_{3}\right)_{2} \mathrm{CCHCH}_{2}+\mathrm{O}_{2}$ reaction (1) at high temperatures. In the kinetic experiments, a product formation signal was observed at $m / z=68$, which was assigned to originate from isoprene. After a reasonable correction $\left(\sim 2.2 \mathrm{kcal} \mathrm{mol}^{-1}\right)$ to the CASPT2 energy of the transition-state pertaining to the channel $\mathrm{R}+\mathrm{O}_{2} \rightarrow$ isoprene $+\mathrm{HO}_{2}$, a good agreement between the respective ME simulated $k_{1 \mathrm{~b}}$ values and the measured $k_{1 \mathrm{~b}}$ values is observed.

\section{Conflicts of interest}

There are no conflicts to declare.

\section{Acknowledgements}

S. P. J. and A. J. E. acknowledge support from the Academy of Finland, grant numbers 294042, 319353, 325250, and 288377. P. S. acknowledges support from the BiofCFD project of the INNO INDIGO ERA-Net S\&T Energy 2016 bio-based energy program funded by the Academy of Finland, grant number 311967. T. T. P. acknowledges support from the Doctoral Programme in Chemistry and Molecular Sciences of the University of Helsinki. The authors wish to acknowledge the CSC-IT Center for Science, Finland, for computational resources.

\section{References}

1 D. Y. Goswami and F. Kreith, Handbook of Energy Efficiency and Renewable Energy, CRC Press, Boca Raton, 2007. 
2 D. M. Alonso, J. Q. Bond, J. C. Serrano-Ruiz and J. A. Dumesic, Green Chem., 2010, 12, 992-999.

3 S. C. Moldoveanu, Pyrolysis of Organic Molecules: Applications to Health and Environmental issues. Elsevier, Amsterdam, 2009.

4 C. K. Law, Combustion Physics, Cambridge University Press, Cambridge, 2010.

5 I. Glassman, R. A. Yetter and N. G. Glumac, Combustion, Academic Press, Cambridge, 5th edn, 2014.

6 C. K. Westbrook, M. Mehl, W. J. Pitz and M. Sjöberg, Combust. Flame, 2017, 175, 2-15.

7 L. Ruwe, K. Moshammer, N. Hansen and K. KohseHöinghaus, Combust. Flame, 2017, 175, 34-46.

8 L. Ruwe, L. Cai, K. Moshammer, N. Hansen, H. Pitsch and K. Kohse-Höinghaus, Combust. Flame, 2019, 206, 411-423.

9 K. Moshammer, L. Seidel, Y. Wang, H. Selim, S. M. Sarathy, F. Mauss and N. Hansen, Proc. Combust. Inst., 2017, 36, 947-955.

10 S. S. Nagaraja, J. Liang, S. Dong, S. Panigrahy, A. Sahu, G. Kukkadapu, S. W. Wagnon, W. J. Pitz and H. J. Curran, Combust. Flame, 2020, 219, 456-466.

11 S. S. Nagaraja, G. Kukkadapu, S. Panigrahy, J. Liang, H. Lu, W. J. Pitz and H. J. Curran, Int, J. Chem. Kinet., 2020, 52, 964-978.

12 C.-W. Zhou, Y. Li, U. Burke, C. Banyon, K. P. Somers, S. Ding, S. Khan, J. W. Hargis, T. Sikes, O. Mathieu, E. L. Petersen, M. AlAbbad, A. Farooq, Y. Pan, Y. Zhang, Z. Huang, J. Lopez, Z. Loparo, S. S. Vasu and H. J. Curran, Combust. Flame, 2018, 197, 423-438.

13 C.-W. Zhou, Y. Li, E. O'Connor, K. P. Somers, S. Thion, C. Keesee, O. Mathieu, E. L. Petersen, T. A. DeVerter, M. A. Oehlschlaeger, G. Kukkadapu, C.-J. Sung, M. Alrefae, F. Khaled, A. Farooq, P. Dirrenberger, P.-A. Glaude, F. BattinLeclerc, J. Santner, Y. Ju, T. Held, F. M. Haas, F. L. Dryer and H. J. Curran, Combust. Flame, 2016, 167, 353-379.

14 W. K. Metcalfe, W. J. Pitz, H. J. Curran, J. M. Simmie and C. K. Westbrook, Proc. Combust. Inst., 2007, 31, 377-384.

15 F. Arafin, A. Laich, E. Ninnemann, R. Greene, R. K. Rahman and S. S. Vasu, Int, J. Chem. Kinet., 2020, 52, 739-751.

16 C. K. Westbrook, W. J. Pitz, M. Mehl, P.-A. Glaude, O. Herbinet, S. Bax, F. Battin-Leclerc, O. Mathieu and E. L. Petersen, J. Bugler and H. J. Curran, J. Phys. Chem. A, 2015, 119, 7462-7480.

17 X. Meng, A. Rodriguez, O. Herbinet, T. Wang and F. BattinLeclerc, Combust. Flame, 2017, 181, 283-299.

18 F. Battin-Leclerc, A. Rodriguez, B. Husson, O. Herbinet, P.-A. Glaude, Z. Wang, Z. Cheng and F. Qi, J. Phys. Chem. A, 2014, 118, 673-683.

19 M. P. Rissanen, D. Amedro, A. J. Eskola, T. Kurten and R. S. Timonen, J. Phys. Chem. A, 2012, 116, 3969-3978.

20 Z. H. Lodhi and R. W. Walker, J. Chem. Soc., 1991, 87, 2361-2365.

21 S. P. Joshi, T. T. Pekkanen, R. S. Timonen, G. Lendvay and A. J. Eskola, J. Phys. Chem. A, 2019, 123, 999-1006.

22 V. D. Knyazev and I. R. Slagle, J. Phys. Chem. A, 1998, 102, 8932-8940.

23 R. R. Baldwin, J. P. Bennett and R. W. Walker, J. Chem. Soc., 1980, 76, 2396-2412.
24 M. Döntgen, T. T. Pekkanen, S. P. Joshi, R. S. Timonen and A. J. Eskola, J. Phys. Chem. A, 2019, 123, 7897-7910.

25 C. F. Goldsmith, L. B. Harding, Y. Georgievskii, J. A. Miller and S. J. Klippenstein, J. Phys. Chem. A, 2015, 119, 7766-7779.

26 X. Chen and C. F. Goldsmith, J. Phys. Chem. A, 2017, 121, 9173-9184.

27 A. J. Eskola and R. S. Timonen, Phys. Chem. Chem. Phys., 2003, 5, 2557-2561.

28 S. Y. Haoyu, X. He, S. L. Li and D. G. Truhlar, Chem. Sci., 2016, 7, 5032-5051.

29 F. Weigend and R. Ahlrichs, Phys. Chem. Chem. Phys., 2005, 7, 3297-3305.

30 Database of Frequency Scale Factors for Electronic Model Chemistries (Version 3 Beta 2), https://comp.chem.umn. edu/freqscale/version3b2.htm, accessed June 2020.

31 T. H. Dunning, Chem. Phys., 1989, 90, 1007-1023.

32 A. Halkier, T. Helgaker, P. Jrgensen, W. Klopper and J. Olsen, Chem. Phys. Lett., 1999, 302, 437-446.

33 T. Helgaker, W. Klopper, H. Koch and J. Noga, J. Chem. Phys., 1997, 106, 9639-9646.

34 M. J. Frisch, G. W. Trucks, H. B. Schlegel, G. E. Scuseria, M. A. Robb, J. R. Cheeseman, G. Scalmani, V. Barone, G. A. Petersson, H. Nakatsuji, X. Li, M. Caricato, A. V. Marenich, J. Bloino, B. G. Janesko, R. Gomperts, B. Mennucci, H. P. Hratchian, J. V. Ortiz, A. F. Izmaylov, J. L. Sonnenberg, D. Williams-Young, F. Ding, F. Lipparini, F. Egidi, J. Goings, B. Peng, A. Petrone, T. Henderson, D. Ranasinghe, V. G. Zakrzewski, J. Gao, N. Rega, G. Zheng, W. Liang, M. Hada, M. Ehara, K. Toyota, R. Fukuda, J. Hasegawa, M. Ishida, T. Nakajima, Y. Honda, O. Kitao, H. Nakai, T. Vreven, K. Throssell, J. A. Montgomery, Jr., J. E. Peralta, F. Ogliaro, M. J. Bearpark, J. J. Heyd, E. N. Brothers, K. N. Kudin, V. N. Staroverov, T. A. Keith, R. Kobayashi, J. Normand, K. Raghavachari, A. P. Rendell, J. C. Burant, S. S. Iyengar, J. Tomasi, M. Cossi, J. M. Millam, M. Klene, C. Adamo, R. Cammi, J. W. Ochterski, R. L. Martin, K. Morokuma, O. Farkas, J. B. Foresman and D. J. Fox, Gaussian16, Revision A.03, Gaussian, Inc., Wallingford, CT, 2016.

35 A. Halkier, T. Helgaker, P. Jørgensen, W. Klopper, H. Koch, J. Olsen and A. K. Wilson, Chem. Phys. Lett., 1998, 286, 243-252.

36 F. J. Neese, Wiley Interdiscip. Rev.: Comput. Mol. Sci., 2012, 2, 73-78. 37 J. P. Zobel, J. J. Nogueira and L. González, Chem. Sci., 2017, 8, 1482-1499.

38 D. R. Glowacki, C.-H. Liang, C. Morley, M. J. Pilling and S. H. Robertson, J. Phys. Chem. A, 2012, 116, 9545-9560.

39 B. E. Poling, J. M. Prausnitz and J. P. O'Connell, The Properties of Gases and Liquids, McGraw-Hill, New York, 5th edn, 2001.

40 C. W. Gao, J. W. Allen, W. H. Green and R. H. West, Comput. Phys. Commun., 2016, 203, 212-225.

41 G. Meloni, P. Zou, S. J. Klippenstein, M. Ahmed, S. R. Leone, C. A. Taatjes and D. L. Osborn, J. Am. Chem. Soc., 2006, 128, 13559-13567.

42 L. G. Dodson, L. Shen, J. D. Savee, N. C. Eddingsaas, O. Welz, C. A. Taatjes, D. L. Osborn, S. P. Sander and M. Okumura, J. Phys. Chem. A, 2015, 119, 1279-1291. 